\title{
1 Identification of Actin Filament Interactors in Giardia lamblia
}

2 Melissa C. Steele-Ogus ${ }^{1}$, Richard Johnson², Michael MacCoss ${ }^{2}$, and Alexander R.

3 Paredez ${ }^{1}$ *

$4 \quad{ }^{1}$ Department of Biology, University of Washington, Seattle, United States

$5 \quad 2$ Department of Genome Sciences, University of Washington, Seattle, United States

$7 \quad$ *Correspondence:

8 Corresponding Author aparedez@uw.edu

\section{Abstract}

11 The deep-branching protozoan parasite Giardia lamblia is the causative agent of the

12 intestinal disease giardiasis. Consistent with its proposed evolutionary position, many

13 pathways are minimalistic or divergent, including its actin cytoskeleton. Giardia is the

14 only eukaryote known to lack all canonical actin-binding proteins. Previously, our lab

15 identified a number of non-canonical Giardia lamblia actin (GIActin) interactors;

16 however, these proteins appeared to interact only with monomeric or globular actin (G-

17 actin), rather than filamentous actin (F-actin). To identify interactors, we used a

18 chemical crosslinker to preserve native interactions, followed by an anti-GIActin

19 antibody, Protein A affinity chromatography, and liquid chromatography coupled to

20 mass spectrometry. We found 46 putative actin interactors enriched in the conditions

21 favoring F-actin. Data are available via ProteomeXchange with identifier PXD026067.

22 None of the proteins identified contain known actin-interacting motifs, and many lacked

23 conserved domains. Each potential interactor was then tagged with the fluorescent 
24 protein $\mathrm{mNeonGreen}$ and visualized in live cells. We categorized the proteins based on

25 their primary localization; localizations included ventral disc, marginal plate, nuclei,

26 flagella, plasma membrane, and internal membranes. One protein from each category

27 was co-localized with GIActin using immunofluorescence microscopy. We also co-

28 immunoprecipitated one protein from each category and confirmed three interactions.

29 Most of the localization patterns are consistent with previously demonstrated GIActin

30 functions, but the ventral disc represents a new category of actin interactor localization.

31 These results suggest a role for GIActin in ventral disc function, which has previously

32 been controversial.

Importance

35 The single-celled eukaryote Giardia lamblia is an intestinal parasite that colonizes the

36 small intestine and causes diarrhea and vomiting, which can lead to dehydration and

37 malnutrition. Giardia actin (GIActin) has a conserved role in Giardia cells, despite being

38 a highly divergent protein with none of the conserved regulators found in model organisms. Here we identify and localize 46 interactors of polymerized actin. These putative interactors localize to a number of places in the cell, underlining GIActin's

41 importance in multiple cellular processes. Surprisingly, eight of these proteins localize to

42 the ventral disc, Giardia's host attachment organelle. Since host attachment is required

43 for infection, proteins involved in this process are an appealing target for new drugs.

44 While treatments for Giardia exist, drug resistance is becoming more common, resulting

45 in a need for new treatments. Giardia and human systems are highly dissimilar, thus

46 drugs specifically tailored to Giardia proteins would be unlikely to have side effects. 
Introduction

Actin is a highly conserved filament-forming protein with essential roles in all

50 eukaryotes that include signaling, motility, membrane trafficking, cell polarity, and

51 cytokinesis (1). Both actin monomers (globular or G-actin) and polymerized actin

52 (filamentous or F-actin) have essential functions in the cell; therefore, the balance

53 between the two forms has a regulatory role in addition to a structural one (2).

54 Eukaryotes throughout the evolutionary tree possess a number of regulators which

55 spatially and temporally control filament formation and depolymerization; their functions

56 include monomer sequestration, filament nucleation or elongation, severing, capping,

57 and crosslinking of filaments (1). Other actin interactors fulfill such roles as linking to

58 organelles and the plasma membrane or moving cargo and generating contractile

59 forces.

The protozoan parasite Giardia lamblia is the only eukaryote known to lack all of

61 the canonical actin-binding proteins (3). Due to the lack of conserved interactors that

62 constrain actin evolution, Giardia possesses the most divergent actin identified to date,

63 and is only $58 \%$ identical to the average eukaryotic actin; in contrast, S. cerevisiae actin

64 and human skeletal actin are $87 \%$ identical $(4,5)$. However, Giardia actin (GIActin)

65 retains conserved roles in many cellular processes, including membrane trafficking, cell

66 polarity, and cytokinesis $(6,7)$. These conserved roles indicate the presence of non-

67 canonical interactors in the proteome (8). The key cellular role of GIActin as well as its

68 extreme divergence could make it and its interactors potential drug targets. Giardia has

69 been designated a neglected disease by the World Health Organization, and giardiasis 
results in millions of cases of diarrheal disease worldwide each year (9).

Our lab previously identified a number of actin-associated proteins in Giardia (10); that study focused on proteins with conserved, identifiable domains whose actinbinding function either may have been overlooked or may not exist in other organisms. Those interactors included microtubule and flagella-related proteins such as p28 and centrin, the chaperone HSP70, the DNA helicase TIP49, the nuclear ARP7, the atypical MAP kinase ERK7, and the regulatory protein 14-3-3.

Much of the Giardia genome contains genes annotated as "hypothetical," as they do not contain any known domains and/or are unique to Giardia. Our previous study identified a number of novel actin-binding partners in Giardia (10) but did not examine these particular proteins. This study also used a twin-strep tag to affinity purify GIActin and did not utilize buffer conditions that stabilize filaments; furthermore, the punctate localization of the interactors described were consistent with that of monomeric actin. Therefore, it is likely that this earlier work may have missed proteins that bind exclusively to filamentous actin and is not a comprehensive list of all the actin interactors in Giardia.

Here, we used a different approach to discover novel GIActin interactors for the purpose of identifying those which bind to F-actin. Using a custom anti-GIActin antibody, Protein A affinity chromatography, and liquid chromatography tandem mass spectrometry (LC -MS/MS), we found a number of novel GIActin interactors. We categorized a subgroup of these putative interactors based on their localization: marginal plate, flagella, ventral disc, nuclei, membrane, and nonspecific. Notably, no previous GIActin interactors have been localized to the marginal plate or the ventral 
93 disc, suggesting that there may be previously unappreciated roles for GIActin in these

94 cellular structures.

\section{Results}

\section{Identification of Non-Canonical GIActin Interactors}

We used a biochemical approach to identify GIActin-binding proteins, utilizing a chemical crosslinker, anti-GIActin antibodies, and Protein A beads. For our purification scheme we used buffers developed for canonical actin; whether these buffers are optimal for GIActin remains untested. Therefore, we also treated the cells with the cleavable chemical crosslinker dithiobis (succinimidyl propionate) (DSP) to ensure the stabilization of native interactions before cell lysis. This molecule reacts with both lysine side chains and the amino terminus of peptides, linking amine groups within 12 angstroms of one another.

In order to differentiate F-actin and G-actin interactors, we lysed wild type cells

107 under these conditions: in G-buffer, expected to favor monomeric actin, followed by

108 DSP treatment, in F-buffer, expected to favor filamentous actin, followed by DSP

109 treatment, or pre-treated with DSP before lysis in F-buffer, expected to stabilize native

110 interactions (Figure 1). We then purified GIActin using an anti-GIActin antibody and

111 Protein A affinity chromatography, and subsequently identified the interactors by LC-

\section{MS/MS.}

Proteins were classified as potential F-actin interactors if they were enriched in

114 either the DSP pre-treated or F-actin buffer conditions in at least two out of three 
116 previously identified as GIActin interactors, including 14-3-3, p28, GASP-180, and

117 others, were also found in this screen, indicating robustness of our methods

118 (Supplemental Table 1). Proteins enriched in the F-conditions but which are common

119 contaminants, such as metabolic, ribosomal, and proteasomal proteins, were also

120 omitted from our analysis. We also omitted the VPS (variant-specific surface proteins),

121 Giardia's surface glycoproteins which undergo antigenic switching $(11,12)$. After

122 exclusion criteria were applied, a total of 46 proteins remained (Table 1). Many of these

123 proteins were annotated as "hypothetical proteins," meaning they lack homologues or

124 known protein domains. Each candidate protein was tagged with the fluorescent protein

$125 \mathrm{mNeonGreen}$ and localized in live and/or fixed cells. Five proteins had non-specific

126 localization or low signal (Supplemental Figure 1, Table 1); the others were grouped into

127 the categories discussed below based on their localization (Figure 2). Despite multiple

128 attempts, we were unable to transform GL50803_21423 (beta adaptin) and thus it is

129 absent from our analysis.

GIActin Interactors in the Nuclei

Giardia has two transcriptionally active nuclei, to which GIActin localizes (6).

133 Previous studies identified conserved GIActin interactors in the nuclei and treatments

134 altering the phosphorylation state of GIActin affected nuclear size $(10,13)$. In model

135 organisms, actin has multiple roles in the nucleus, including chromatin remodeling and

136 regulating transcription (14).

137 Our screen discovered six nuclear localized proteins, each with a distinct 138 sublocalization (Figure 3). GL50803_5238 (sigma adaptin, a component of the AP-2 
139 complex) appeared in puncta within the nuclei and in association with the cell cortex.

141 encysation (15), was also localized in the cytoplasm, with some large puncta, as well as

142 a slight enrichment in the marginal plate. The protein appears somewhat more

143 concentrated towards the anterior of the nuclei. GL50803_GL14299 (hypothetical)

144 appeared to be associated with the nuclear envelope in puncta. GL50803_33989

145 (hypothetical) was previously tagged with a C-terminal GFP tag and formed inclusion

146 bodies in cells $(16,17)$, so we tagged this protein $\mathrm{N}$-terminally under its native promoter.

147 Under these conditions, GL50803_33989 localized to the nuclei, forming structures

148 which may be filamentous. The perinuclear localization of GL50803_101212

149 (hypothetical) may represent the perinuclear endoplasmic reticulum. In contrast,

150 GL50803_14213 (coiled coil domain) has no puncta or other sub-pattern within the

151 nuclei.

152

153 GIActin Interactors in the Flagella

154 Giardia's four sets of flagella have different cellular roles and undergo a complex

155 developmental cycle $(18,19)$. Actin is a key component of flagella; in Chlamydomonas, 156 six of the seven inner dynein arms form a complex with actin (20). Additionally, actin is 157 an important regulator of intraflagella transport and the regulation of flagella length (21).

158 Anti-GIActin immunostaining showed its clear localization within the flagella, and as a

159 helix that surrounds the caudal flagella, similar to actin organization of the sperm

160 midpiece (22). Our previous study identified six axonemal dynein heavy chains in

161 addition to p28 as GIActin interactors (10). Thus, finding six flagellar-localized proteins 
162 in this screen is consistent with previous knowledge (Figure 4). Three of these

163 candidate GIActin interactors are dynein light chains; while all appeared in the

164 cytoplasm in low levels, each had their own unique flagellar localization pattern.

165 GL50803_15124 localized to the entirety of the flagella axonemes, while

166 GL50803_9848 appeared primarily associated with the cytoplasmic portions of

167 axonemes. GL50803_4463 had similar axonemal localization, and additionally localized

168 in patches throughout the cell in low levels. GL50803_15097 (alpha-14 giardin)

169 enrichment was less intense in the anterior flagella than the other three flagella pairs.

170 GL50803_33685 (armadillo repeat) appeared throughout the flagella but was

171 particularly enriched in the axonemes. In contrast, GL50803_13774 (hypothetical)

172 appeared only in the flagellar pores, the structures where the flagella exit the cell.

174 GIActin Interactors in the Marginal plate

175 Seven proteins in our screen localized to the marginal plate (Figure 5), a lattice-

176 like structure at the anterior of the cell which is associated with the axonemes of the

177 anterior flagella (23). Ultra-high resolution scanning electron microscopy showed flexible

178 filaments at the plate $(24,25)$, and immunofluorescence revealed enriched GIActin there

$179(10,25)$. Little else is known about the function or composition of the marginal plate; it

180 has been suggested to have a role in attachment, but this has remained an unexplored

181 area of research $(6,8,26)$

$182 \quad$ Notably, multiple proteins in the marginal plate also localized to microtubule-

183 based structures. For instance, GL50803_8854 (hypothetical) also localized to the

184 flagellar pores, GL50803_17153 (alpha-11 giardin) appeared faintly in the disc 
185 (Supplemental Figure 2), and GL50803_5800 (hypothetical) was slightly enriched in the axonemes. GL50803_17153, GL50803_4383 (ankyrin repeat protein), and

GL50803_115478 (ankyrin repeat) also appeared as puncta or linear stretches near the contact with the surface of substrates during attachment (29).

\section{GIActin Interactors in Internal Membranes}

Although Giardia lacks many organelles, including a Golgi, lysosomes, and peroxisomes, it still has a defined endomembrane system. GIActin is important for receptor-mediated endocytosis, membrane remodeling during abscission, and the

202 trafficking of cyst wall protein during encystation $(6,8,30)$.

204 membrane-bound compartments (Figure 6). Intriguingly, GL50803_12999 (hypothetical)

205 localized to a previously undescribed organelle as well as puncta that could be

206 peripheral vacuoles and the ER. GL50803_9861 (hypothetical) also had a punctate 207 localization which could represent small vesicles. Apart from the previously mentioned 
208 GL50803_101212, which may be in the perinuclear ER, two proteins localize to internal

209 structures which we suspect to be the endoplasmic reticulum: GL50803_22855

210 (hypothetical) and GL50803_13930 (Arf3). GL50803_22855 (hypothetical) appeared to

211 be localized throughout the entirety of the organelle, whereas the puncta of

212 GL50803_13930 (Arf3) are consistent with the ER exit sites (31).

213

214 GIActin Interactors at the Cortex and Plasma Membrane

We found ten putative interactors which localized to the cell cortex, composing

216 the largest group in the screen. This is consistent with GIActin and actin in general

217 having roles in regulating cell shape, cell polarity, and membrane trafficking (Figure 7).

218 Despite a shared generalized localization, each putative interactor had its own individual

219 pattern. The internal membrane localization of GL50803_8044 (7 transmembrane

220 domain) localizes to both the plasma membrane and ER. In this case we are confident

221 the protein is in the ER, as transmembrane proteins are necessarily trafficked through

222 this organelle. Both GL50803_14551 (alpha-6 giardin) and GL50803_17255

223 (hypothetical) appeared in the ventrolateral flange, a thin membranous structure that

224 protrudes from the plasma membrane and contributes to parasite attachment $(32,33)$.

225 GL50803_23833 (VPS35), GL50803_103855 (VPS29), GL50803_8560 (hypothetical),

226 GL50803_15591 (coil coil protein), GL50803_4259 (clathrin light chain), and

227 GL50803_11684 (leucine rich repeat protein) all had a punctate localization at the cell 228 cortex, likely in association with the plasma membrane. 


\section{GIActin Interactors in the Ventral Disc}

The ventral adhesive disc is a microtubule-based structure unique to Giardia,

233 which allows cells to attach to the small intestine of their host, or to the side of a culture

234 tube in vitro. The dome-shaped disc is composed of roughly 100 microtubules which

235 form a stable sheet that wraps into a spiral and overlaps itself (34). In the center of the

236 disc is the bare area, a region devoid of microtubules but containing membrane-bound

237 vesicles involved in membrane trafficking (29). GIActin's role in the disc, if any, has

238 heretofore been controversial (35).

Eight putative GIActin interactors localized to the disc, representing the second

240 largest group of putative interactors. GL50803_8726, GL50803_16844, GL50803_4239, and GL50803_17230 had not been localized when we started this work, but have since been identified as disc-associated proteins (DAPs) (17), they are included here for the

243 sake of completeness. GL50803_27925, GL50803_113622, GL50803_24451, and

244 GL50803_11354 are new DAPs.

245 The localizations within the ventral disc varied widely (Figure 8). Four of these

246 proteins have no recognized domains, including GL50803_8726, which localized to the

247 entirety of the ventral disc in addition to the median body, a reservoir of microtubules

248 supporting rapid disc assembly during mitosis (36). GL50803_16844 (hypothetical),

249 GL50803_4239 (hypothetical), and GL50803_1720 (gamma-giardin) were also localized

250 to the entirety of the disc, but enriched in various regions within it. Both

251 GL50803_11354 (hypothetical) and GL50803_24451 (FGF domain) had less distinct

252 localizations. The remaining two disc-localized proteins have ankyrin-repeat domains, 253 and coincidentally had inverse patterns of localization: while GL50803_27925 appeared 
254 everywhere in the disc except the ventral groove, GL50803_113622 localized to only

255 the ventral groove.

256

257 Co-localization of Candidate Interacts with GIActin

As there is no live GIActin marker, we performed immunofluorescence assays on

259 one protein per category of localization with an anti-GIActin antibody to co-localize them

260 (Figure 9). Phalloidin does not bind to GIActin (6), so polymerized GIActin is difficult to

261 distinguish from pools of monomeric GIActin in fixed cells. Similarly, because GIActin is

262 ubiquitously distributed throughout the cell, co-localization is not easily discerned. We

263 used the JACoP plugin from ImageJ to evaluate co-localization. Based on Pearson's

264 Correlation Coefficients (PCC), the most prominent co-localization between GIActin and

265 its putative interactors can be seen in the internal membrane protein GL50803_22855

266 and GL50803_13774, which localizes to the flagellar pores. The marginal plate protein

267 GL50803_9030 and the nuclear localized GL50803_102813 also had PCCs > 0.5,

268 indicating co-localization.

269 In order to validate association with GIActin for a subset the identified proteins,

270 we made $3 \mathrm{xHA}$ constructs to perform co-immunoprecipitations. We chose one protein

271 per category based on its presence in all three replicates. The exception is

272 GL50803_8854, as none of the proteins from the marginal plate category were found in

273 all three replicates. We chose GL50803_8854 based on its high expression and

274 presence at both the marginal plate and flagellar pores, structures where GIActin is

275 enriched. We were able to confirm complex formation between GIActin and 
277 membrane). Association between GIActin and GL50803_12999 (internal membranes)

278 was ambiguous (Figure 10), possibly due to the latter's association with membranes

279 and/or low expression. The nuclear interactor GL50803_33989 did not express at high

280 enough levels to be visible on a western blot (data not shown). Our co-

281 immunoprecipitation results confirm that we have identified GIActin-associated proteins,

282 increasing our confidence in the data presented here. It should be noted, however, that

283 despite its co-localization with GIActin, the flagellar pore protein GL50803_13774 did

284 not co-immunoprecipitate with GIActin. This does not necessary indicate that they do

285 not interact; the $3 \times \mathrm{xHA}$ tag could have intefered with the interaction. Another possibility is

286 that the interaction is too weak to be detected by western blot, since LC-MS/MS is a

287 more sensitive technique.

Discussion:

We performed LC-MS/MS to identify putative GIActin interactors and found them

291 to localize to multiple regions within the cell, including the nuclei, plasma membrane,

292 endomembrane system, marginal plate, flagella, and ventral disc. We also found a

293 number of previously validated GIActin-binding proteins (Supplemental Table 1) as well

294 as several proteins which had already been localized in live cells by the Dawson lab

295 (UC Davis) as part of the Giardia genome database project (Supplemental Table 2)

296 (17). Seventeen of the proteins in this screen have no recognizable identity and lack

297 conserved domains; thus, we were unable to find any clues to their function within their

298 sequence. We also used I-TASSER to search for structural homologs, but this search

299 too yielded no results (35). Six proteins identified in our screen contained ankyrin repeat 
300 domains, scaffolds for protein recognition and interaction, which are present in actin 301 regulators in other organisms $(37,38)$. We also found four alpha-giardins, annexin-like cytoskeletal proteins unique to Giardia (39). The membrane-localized alpha-6 giardin may have a role in membrane organization, similar to the canonical annexin A-II, which binds F-actin and mediates its interactions with membranes $(40,41)$. to Giardia's two nuclei. When immunostained, GIActin is visible in the nuclei; our lab previously demonstrated roles for GIActin in nuclear positioning and size $(6,10,13)$. has a role in gene regulation through formation of the pre-initiation complex and in

311 chromatin remodeling through its association with the BAF complex $(42,43)$. In

312 contrast, F-actin has a role in intranuclear mobility, WNT-dependent transcription, and

313 nuclear stability $(14,42,44)$. Notably, most of these functions depend on nuclear

314 myosins, which are missing from the Giardia genome (3); however, it is still possible 315 that GIActin fulfills these functions, particularly since a number of our putative 316 interactors localize to the nuclei.

In model organisms, actin also works not only within but immediately around the

318 nucleus for protection, as well as anchoring the nucleus and in nuclear positioning

319 during mitosis, mediated by the Linker of Nucleoskeleton and Cytoskeleton (LINC)

320 complex $(44,45)$. While Giardia lacks the LINC complex $(6)$, it is likely that actin is still

321 involved in nuclear positioning, since GIActin knockdowns results in mislocalized nuclei $322(6)$. 
In model eukaryotes, the Arp2/3 complex drives actin polymerization to mediate

324 clathrin-coated pit internalization, which is nucleated by the AP-2 complex (46).

Although GIActin's role in membrane trafficking has been demonstrated, its possible involvement in clathrin-mediated endocytosis remains controversial (47-49). However,

327 the presence of the putative clathrin light chain among our interactors points to some

328 involvement. Recent evidence also suggests GIActin interacts with clathrin heavy chain

329 (50). Due to the absence of most conserved endocytic proteins, the mechanism for

330 clathrin-mediated endocytosis in Giardia is poorly understood. The clathrin heavy chain

331 has been demonstrated to interact with components of the AP-2 adaptor complex,

332 specifically alpha and beta adaptins, which localize to the plasma membrane (51). The

mu subunit of AP-2 has been localized to the hybrid endosome/lysosome peripheral

335 adaptin, central to the structure of the AP-2 complex (53-55), localize to the nucleus in

336 addition to the plasma membrane. However, some of the other adaptins, notably alpha

337 adaptin, have a function in nuclear translocation (56); it is possible that both sigma has both nuclear and plasma membrane localization.

34135 , are subunits of the cargo recognition particle of the retromer complex. Retromer is

342 involved in the endosome-to-Golgi retrograde transport pathway and mediates the

343 recycling of membrane receptors in yeast and mammals (57). Previous work in Giardia,

344 which shows VPS29 localizing to the ER, conflicts with our results; however, the

345 previous study used an HA-tagged protein that was localized in fixed cells. However, 
346 the same study localized VPS35 to the plasma membrane (58), so it is expected that at

347 least a subset of VPS29 would also localize to the plasma membrane. While VPS26,

348 the other subunit of the cargo recognition particle, did not fit our criteria for possible F-

349 GIActin interactors, it did appear in our screen (Supplemental Table 3). Since there is no

350 Golgi in Giardia and the sorting nexins which constitute the other retromer subunit are

351 also missing from the Giardia genome, the role of Giardia's cargo recognition particle is

352 unknown. VPS35 has been shown to bind to hydrolase, but its function in doing so was

353 not explored (58). Furthermore, while the canonical VPS35 is known to coordinate with

354 actin through interaction with FAM21 and the WASH complex (59), these are also

355 absent in Giardia.

While the Giardia genome lacks moesin, ezrin, radixin, or any ERM domain

357 proteins, GIActin does localize to the cellular cortex, so one or more of the putative

358 interactors also localized here could fulfill the role of a cortical crosslinker. Furthermore,

359 GIActin-depleted cells have defects in cell polarity and cell shape (6). Another possible

360 role for GIActin interactors localized to the plasma membrane is in phagocytosis, a

361 process previously unrecorded in Giardia, but for which evidence has recently been

362 published (60); if further research shows Giardia to be capable of phagocyotis, GIActin is

363 likely to be involved $(60,61)$, given its role in phagocytosis in other organisms.

In addition to their presence in the plasma membrane, both the alpha-giardin

365 GL50803_14551 and the hypothetical protein GL50803_17255 also extended into the 366 ventrolateral flange (VLF), the hypothesized membrane reservoir that skirts Giardia cells.

367 Short GIActin filaments appear in the VLF, and another novel actin interactor, Flangin, 
368 has been implicated in its function (32); it is likely that more of these interactors are

369 382 location. important for maintenance and function of the VLF.

Many of our newly identified interactors localize to axonemes. Actin is a key component of the flagella inner dynein arm, although the actin within the inner arm is monomeric and complexed with a p28 homodimer (62); additionally, actin appears to play a structural role in $\mathrm{Y}$-TURC (63). Immunostaining indicates GIActin to be within the flagella and we have previously identified p28 as an interactor $(20,64)$. Actin's role in the flagella of other organisms is not merely structural; for instance, actin polymerization is required for flagellar biogenesis and intraflagellar transport in Chlamydomonas reinhardtii $(65,66)$. Morpholino knockdown of GIActin results in flagella which are mispositioned or even missing, implicating GIActin in flagellar positioning (6). The two flagellar pore interactors we identified could also be involved in this process; future studies could investigate the role of these proteins through depletion to test if resulting flagella lack stability, are trapped within the cell body, or exit the cell at an incorrect

Despite the reduction of Giardia's endomembrane system, it has a relatively conventional ER, and two of our proteins had ER-like localizations, consistent with GIActin's previously established role in membrane trafficking. Two others, GL50803_12999 (hypothetical) and GL50803_8044 (7 transmembrane domain) localize to an undescribed compartment. Since Giardia has unique organelles such as the Golgilike encystation specific vesicles, it is likely that more compartments exist in Giardia than are currently recognized and these proteins may be involved in their function. 
The marginal plate, a crescent-shaped structure at the anterior of the cell, has

391 not yet been functionally studied, limiting our ability to infer the function of the proteins

392 located there. While it has been suggested to be involved in attachment, this role is speculative. Since immunofluorescence assays show enrichment of GIActin at this site,

394 it is possible that the meshwork of filaments seen in electron micrographs (67)are

395 composed of GIActin or that GIActin acts upon this structure. Intriguingly, after 396 depletion, GIActin localization persists at the marginal plate, suggesting that the

397 associated GIActin is highly stabilized (13). ventral disc is perhaps the most surprising. One previous study localized GIActin to the 400 ventral disc (68); however, this study used a heterologous antibody, raised against 401 chicken gizzard actin, for immunostaining. This finding is almost certainly an artifact, 402 given that the same study found similar localization patters for actin-binding proteins not 403 present in the Giardia proteome (68). While the disc itself is composed of microtubules, 404 their polymerization dynamics are not responsible for flexation and/or attachment; it is 405 possible that GIActin, as a force-generating protein, plays a role in this process.

406 Giardia's ability to attach, and thus its health, depends on the disc, and as this structure 407 is unique to Giardia, many of the proteins that localize there have no relationship to 408 proteins in other organisms. It is noteworthy that the different disc proteins had different 409 localizations, indicating that the different regions of the disc may have different 410 relationships to GIActin. Perhaps most notable are GL50803_16844 and

411 GL50803_113644, as they are highly enriched in the margin near the overlap zone 412 and/or the ventral groove; these regions are hypothesized to regulate fluid flow beneath 
413 the ventral disc (69). While GIActin does not appear concentrated in the ventral disc in

414 immunofluorescence images, this could be due to steric hindrance between the

415 antibody and proteins on the ventral disc, similar to the faint tubulin immunostaining

416 seen in the disc compared to the amount of signal observed when using fluorescently-

417 tagged tubulin (36). Another possibility is that F-actin is localized to the disc, but it is

418 obscured by the pool of monomeric GIActin in our immunostaining. Defects in one of our

419 disc-localized interactors, gamma-giardin, results in misshapen discs, but normal

420 adherence, suggesting the role of gamma-giardin to be structural rather than actively

421 mechanical (70). Notably, over half of our interactors with previously reported

422 localizations are at the ventral disc (Supplemental Table 2) $(17,71)$.

423 Here we have characterized a number of putative GIActin interactors, with a

424 diversity of localizations and possible applications. Study of GIActin is challenging as we

425 still lack a live marker for actin in Giardia and markers that generally recognize actin in

426 other eukaryotes, such as LifeAct, F-tractin, and Utrophin, do not label filamentous

427 structures in Giardia. The proteins identified in our study could be truncated to potentially

428 be used as a live GIActin marker, but development of such a tool would be difficult in

429 those which lack identifiable domains. Of particular interest are the proteins which localize

430 to the ventral disc, the ventrolateral flange, and the marginal plate. If, as hypothesized,

431 the plate is important for attachment, this work has potentially uncovered a connection

432 between GIActin and all of Giardia's mechanisms for attachment, which is required for

433 maintaining infection. Thus, there are ample opportunities for drug development in further

434 study of these proteins, particularly since few of them have homologues in humans. 


\section{Materials and Methods}

437 Parasite Strain and Growth Conditions

438 G. lamblia strain WB clone 6 (ATCC 50803; American Type Culture Collection) was

439 cultured under standard conditions (72).

\section{Lysis and Crosslinking}

$4423 \mathrm{~L}$ of wild type Giardia trophozoite culture was grown to confluence in $1 \mathrm{~L}$ bottles as

443 described previously (10). Cells were iced for 2 hours to induce detachment, then

444 centrifugation for 30 minutes at $1500 \mathrm{xg}$ at $4^{\circ} \mathrm{C}$, then washed twice with 1 XHBS (HEPES

445 buffered saline) plus 1xHALT protease inhibitor cocktail (Thermo Scientific Catalog

446 number 78430 ) by resuspension and centrifugation for 15 minutes at $1500 \mathrm{xg}$ at $4^{\circ} \mathrm{C}$.

447 Each culture was then resuspended in $1.6 \mathrm{~mL}$ of buffer. Two were resuspended in F-

448 buffer (20 mM HEPES, $0.2 \mathrm{mM} \mathrm{CaCl} 2,80 \mathrm{mM} \mathrm{KCl}, 10 \mathrm{mM}$ imidazole, $1 \mathrm{mM} \mathrm{MgCl} 2,1$

449 mM EGTA, 5\% Glycerol, 10 mM ATP, 1X HALT protease inhibitors, pH 7.2) while one

450 was resuspended in G-Buffer (20 mM HEPES, $0.2 \mathrm{mM} \mathrm{CaCl}$, $0.2 \mathrm{mM}$ ATP, 1X HALT

451 protease inhibitors, $\mathrm{pH} 7.2$ ).

452 One of the F-buffer cultures was then treated with crosslinker DSP

453 (dithiobis(succinimidyl propionate)) (Thermo Scientific Catalog number 22585) to a final

454 concentration of $1 \mathrm{mM}$ and incubated for 30 minutes at room temperature, quenched

455 with Tris- $\mathrm{HCl} \mathrm{pH} 7.5$ to a final concentration of $20 \mathrm{mM}$ and incubated at 15 minutes, then

456 lysed in the manner described below. The other F-buffer culture and the G-buffer culture

457 were lysed with sonication, pulse for 25 seconds each at $20 \%$ power with 1 -minute rest

458 between each sonication, repeated a total of 4 times minimum. Sonicated cells were 
459 allowed to rest on ice for 30 minutes, then cleared with a 10,000xg spin for 10 minutes

460 at $4^{\circ} \mathrm{C}$. The supernatant of these two cultures was then treated with DSP crosslinker to

461 a final concentration of $1 \mathrm{mM}$ and incubated for 30 minutes at room temperature,

462 quenched with Tris- $\mathrm{HCl} \mathrm{pH} 7.5$ to a final concentration of $20 \mathrm{mM}$ and incubated at 15

463 minutes. This was repeated for a total of three independent replicates per condition.

\section{Purification and Sample Preparation for Mass Spectrometry}

466 Lysates were incubated overnight with an anti-GIActin antibody (6) at $4^{\circ} \mathrm{C}$, then

467 incubated with $500 \mu \mathrm{L}$ Pierce ${ }^{\mathrm{TM}}$ Protein A agarose (Catalog number 20333) bead slurry

468 and incubated with end-to-end mixing for 2 hours at room temperature. A total of four

469 washes were performed by addition of $0.5 \mathrm{~mL}$ of wash buffer (G- or F-Buffer with an

470 additional $150 \mathrm{mM} \mathrm{NaCl}$ ), vortexed, and centrifuged for 2-3 minutes at 2500xg. For

471 elution, $250 \mu \mathrm{L}$ of $0.2 \mathrm{M}$ Glycine $\mathrm{pH} 2.5$ was added to the beads and incubated for 5

472 minutes, centrifuged for 3 minutes at $2500 x g$, and the supernatant was collected. This

473 step was then repeated and the two eluate fractions were combined. The pH was then

474 neutralized through addition of $50 \mu \mathrm{L} 1 \mathrm{M}$ Tris- $\mathrm{HCl} \mathrm{pH} 7.5$.

475

476 For each condition, 5X sample buffer (0.225 M Tris-HCl, $\mathrm{pH} 6.8,50 \%$ glycerol, 5\% SDS,

$4770.05 \%$ bromophenol blue, $0.25 \mathrm{M} \mathrm{DTT}$ ) was added to a final concentration of $1 \mathrm{X}$

478 subsequent to running on a 10\% SDS-PAGE gel and stained with SYPRO Ruby

479 (Pierce). Bands corresponding to the heavy and light antibody chains were excised from

480 the gel and discarded; the remainder of the gels were divided into rectangles of

481 approximately equal size. These rectangles were cut into squares of approximately 1-2 
$482 \mathrm{~mm}$, washed with $200 \mu \mathrm{L}$ water, then incubated with $200 \mu \mathrm{L}$ of $50 \%$ acetonitrile and 25

$483 \mathrm{mM}$ ammonium bicarbonante for 5 minutes. After addition of another $200 \mu \mathrm{L}$ acetonitrile

484 and further incubation for 1 minute, the gel was dried with a speed vacuum, followed by

485 another addition of $50 \mu \mathrm{L}$ of $25 \mathrm{mM}$ ammonium bicarbonate and $10 \mathrm{mM}$ TCEP. Samples

486 were then incubated at $60^{\circ} \mathrm{C}$ for 1 hour, after which the supernatant was removed and

487 replaced with $50 \mu \mathrm{L}$ of $25 \mathrm{mM}$ ammonium bicarbonate and $10 \mathrm{mM}$ iodacetamide, then

488 incubated for 20 minutes in the dark. Another wash was performed with $400 \mu \mathrm{L}$ water

489 and the 5-minute incubation with $200 \mu \mathrm{l} 50 \%$ acetonitrile, $25 \mathrm{mM}$ ammonium

490 bicarbonate and following steps were repeated. Protein samples were then digested

491 with $20 \mu \mathrm{L}$ of $0.01 \mu \mathrm{g} / \mu \mathrm{L}$ Promega Trypsin in $25 \mathrm{mM}$ ammonium bicarbonate. More

492 ammonium bicarbonate was added to cover, followed by overnight digestion.

493 Supernatant was then removed for LC/MS-MS analysis. Protein was further extracted

494 from the gels by addition of $50 \mu \mathrm{L}$ of acetonitrile, vortexing, and removing and saving

495 supernatant. One last extraction was performed by addition of $50 \mu \mathrm{L} 60 \%$ acetonitrile,

$496 \quad 0.1 \%$ formic acid, vortexing for 5 minutes, and then removing the supernatant. The

497 supernatants were then combined, dried, and resuspended in solvent $A$, then analyzed

498 by LC/MS-MS as described below.

499

500 Liquid Chromatography and Mass Spectrometry

501 Liquid chromatography - mass spectrometry was performed on a Velos Pro (Thermo)

502 with an EasyLC 1000 HPLC and autosampler (Thermo). Samples were solubilized in

503 loading buffer ( $0.1 \%$ trifluoroacetic acid and $2 \%$ acetonitrile in water), and 6 ul was

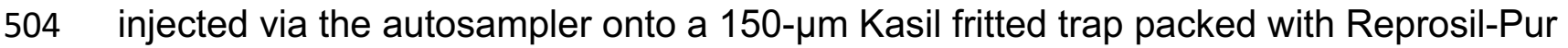


505 C18-AQ (3- $\mu \mathrm{m}$ bead diameter, Dr. Maisch) to a bed length of $2 \mathrm{~cm}$ at a flow rate of 2

$506 \mathrm{ul} / \mathrm{min}$. After loading and desalting using a total volume of 8 ul of loading buffer, the

507 trap was brought on-line with a pulled fused-silica capillary tip (75- $\mu \mathrm{m}$ i.d.) packed to a 508 length of $25 \mathrm{~cm}$ with the same Dr. Maisch beads. Peptides were eluted off the column

509 using a gradient of 2-35\% acetonitrile in $0.1 \%$ formic acid over 90 minutes, followed by

$51035-60 \%$ acetonitrile over 5 minutes at a flow rate of $250 \mathrm{nl} / \mathrm{min}$. The mass spectrometer

511 was operated using electrospray ionization $(2 \mathrm{kV})$ with the heated transfer tube at $200 \mathrm{C}$

512 using data dependent acquisition (DDA), whereby a mass spectrum (m/z 400-1600,

513 normal scan rate) was acquired with up to $15 \mathrm{MS} / \mathrm{MS}$ spectra (rapid scan rate) of the

514 most intense precursors found in the MS1 scan.

Database searches were performed using Comet (73) searched against the

516 protein sequence database GiardiaDB

517 3.1_GintestinalisAssemblageA_AnnotatedProteins.fasta to which was appended

518 sequences of common contaminants (e.g., human keratins). The peptide mass

519 tolerance was $3 \mathrm{Da}$, and the fragment ions were sorted into $1 \mathrm{Da}$ bins (roughly

520 corresponding to a fragment ion mass tolerance of +/- 0.5 Da). Semi-tryptic cleavages

521 and up to two missed tryptic cleavage sites were allowed. Oxidized methionine and

522 acetylation of the protein N-termini were allowed as variable modifications.

523 Carbamidomethylated cysteine was a fixed modification. False discovery rates (1\%)

524 were determined using PeptideProphet (74), and protein inferences were made using

525 ProteinProphet (75). Spectral count analysis was performed using Abacus (76).

526

527 


\section{Data Availability}

529 The mass spectrometry proteomics data have been deposited to the ProteomeXchange

530 (77) Consortium via the PRIDE partner repository with the dataset identifier PXD026067

531 (78). Reviewer account details: Username: reviewer_pxd026067@ebi.ac.uk Password:

532 v05lifYI

533

534 Bioinformatics

535 Delta-BLAST, Protein BLAST, and Pfam searches were used to identify homologues

536 and conserved domains for each putative interactor. I-TASSER was used to search for

537 structure-based function prediction.

538

539 Vector Construction

540 All constructs in this study were C-terminal fusions with the exception of the N-terminally

541 tagged GL50803_33989 and GL50803_7323, using Gibson reactions with linearized

542 vectors and PCR products $(7,79)$. For primer sequences and workflow, see

543 Supplemental Table 4.

544

545 Immunofluorescence Microscopy

546 Fixation and imaging were performed as described in previous work (80). FIJI/ImageJ

547 were used for image analysis, including co-localization analysis by Just Another

548 Colocalization Plugin (JACoP) (81). 


\section{Live Cell Imaging}

552 Cells were chilled with ice for 15 minutes to detach from the culture tube and then

553 placed into an Attofluor cell chamber (Molecular Probes) and incubated in a GasPak EZ

554 anaerobic pouch (BD) or a Tri-gas incubator (Panasonic) set to 2.5\% O2, 5\% Co2 for 90

555 minutes at $37^{\circ} \mathrm{C}$. Cells were then washed four times with HEPES-buffered saline

556 (137mM NaCl, 5mM KCl, 0.91mM Na2HpO4-heptahydrate, 5. 55mM Glucose, 20mM

557 HEPES, and $\mathrm{pH} 7$ ), overlaid with a mixture of $0.7 \%$ ultra-low gelling agarose (Sigma

558 A2576) melted in HEPES-buffered saline, cooled for 10 minutes at room temperature to

559 solidify, then imaged. Live cell imaging was performed on a DeltaVision Elite

560 microscope (GE) equipped with DIC optics, using a 100X 1.4 NA or 60X 1.42 NA

561 objective, and a sCMOS 5.4 PCle air-cooled camera (PCO-TECH).

562

563 Co-immunoprecipitation

$564500 \mathrm{~mL}$ of Giardia cell cultures were grown for 3 days, then iced for 2 hours to detach

565 and spun for $1500 x g$ at $4^{\circ} \mathrm{C}$. Cells were then washed twice in HBS with 2 XHALT

566 protease inhibitors and $10 \mu \mathrm{M}$ chymostatin, $1 \mu \mathrm{M}$ leupeptin, and $1 \mu \mathrm{M}$ E64.

567 Each pellet was resuspended to a final volume of $1.2 \mathrm{~mL}$ and $100 \mathrm{mM}$ DSP in DMSO

568 was added to a final concentration of $1 \mathrm{mM}$ and incubated at room temperature for 30

569 minutes. The reaction was quenched for 15 minutes with an addition of $\mathrm{Tris}-\mathrm{HCl} \mathrm{pH} 7.4$

570 final concentration $20 \mathrm{mM}$. Cells were then pelleted by spinning for 7 minutes at $700 \times g$

571 and resuspended in $350 \mu \mathrm{L}$ lysis buffer $(80 \mathrm{mM} \mathrm{KCl}, 10 \mathrm{mM}$ imidazole, $1 \mathrm{mM} \mathrm{MgCl}$, 1

572 mM EGTA, 5\% Glycerol, 20 mM HEPES, 0.2 mM, CaCl2, 10 mM ATP, 0.1\% Triton X-

$573100,500 \mathrm{mM} \mathrm{NaCl}, \mathrm{pH}$ 7.2). 
574 Cells were then lysed by sonication as and cleared as described above. A volume of

$57517.5 \mu \mathrm{L}$ of equilibrated EZview Red Anti-HA Affinity gel (Sigma) was added to each tube

576 of lysate, then incubated at $4^{\circ} \mathrm{C}$ with end-over-end mixing for 1 hour. Beads were then

577 spun at 8,200xg for 30 seconds and the supernatant was discarded, followed by a total

578 of three washes with $750 \mu \mathrm{L}$ wash buffer $(80 \mathrm{mM} \mathrm{KCl}, 10 \mathrm{mM}$ imidazole, $1 \mathrm{mM} \mathrm{MgCl} 2,1$

579 mM EGTA, 5\% Glycerol, 20 mM HEPES, 0.2 mM CaCl2, 10 mM ATP, 0.5\% Tween,

$580500 \mathrm{mM} \mathrm{NaCl}, \mathrm{pH}$ 7.2). Each wash consisted of end-over-end rotation for 5 minutes

581 followed by a 30 second spin at $8,200 x g$. Protein was then incubated with $50 \mu \mathrm{L}$ of $8 \mathrm{M}$

582 Urea at RT for 20 minutes to elute, followed by addition of 5X sample buffer (QIAGEN)

583 to a final concentration of $1 \mathrm{X}$, boiled for 5 mins at $98^{\circ} \mathrm{C}$, and run on $12 \%$ SDS-PAGE

584 gel, followed by Western blot protocol described previously (7). 


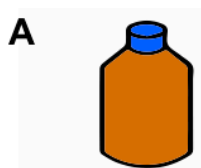

$1 \mathrm{~L}$ of WT Culture

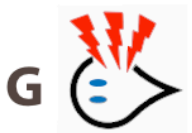

Lysis in G Buffer

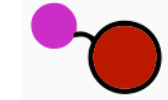

Crosslinking

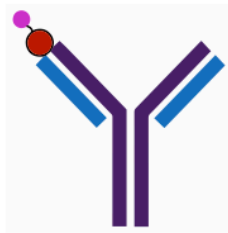

Antibody Incubation

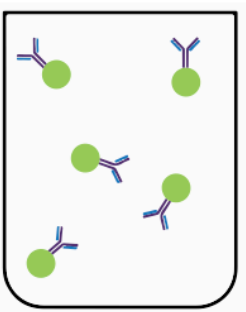

Protein A Chromatography
B

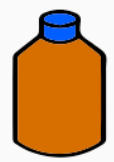

$1 \mathrm{~L}$ of WT Culture

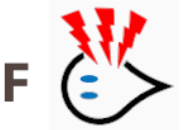

Lysis in F Buffer
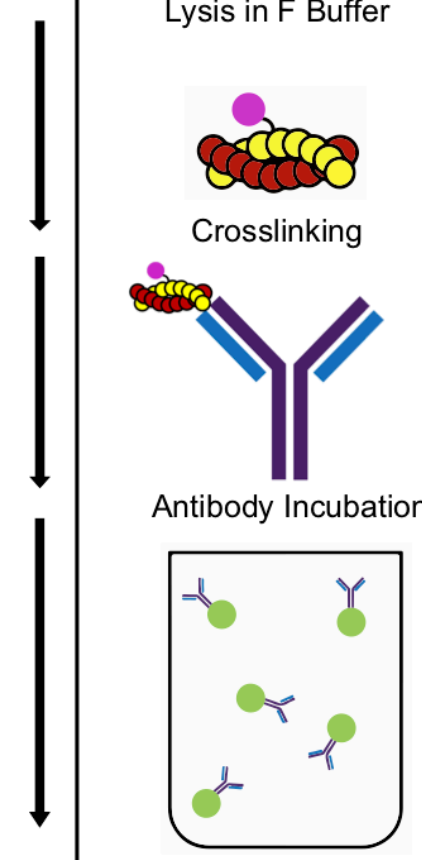

Antibody Incubation

D

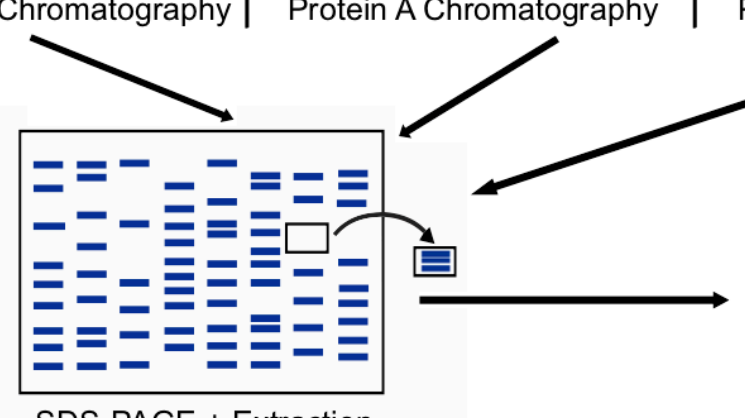

SDS-PAGE + Extraction

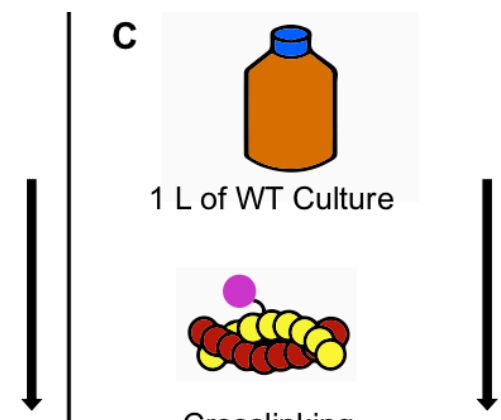

Crosslinking

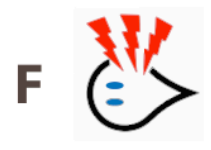

Lysis in F Buffer

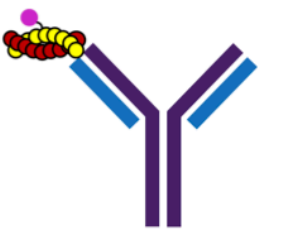

Antibody Incubation

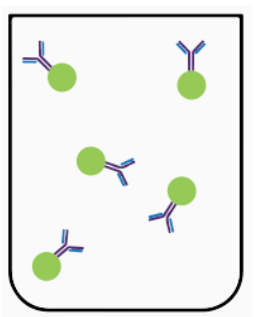

Protein A Chromatography

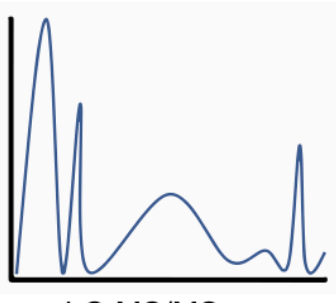

LC-MS/MS

Figure 1: Schematic of methods $1 \mathrm{~L}$ of cells was lysed under one of the following

conditions: (A) in G-buffer followed by crosslinking , (B) F-buffer followed by crosslinking 


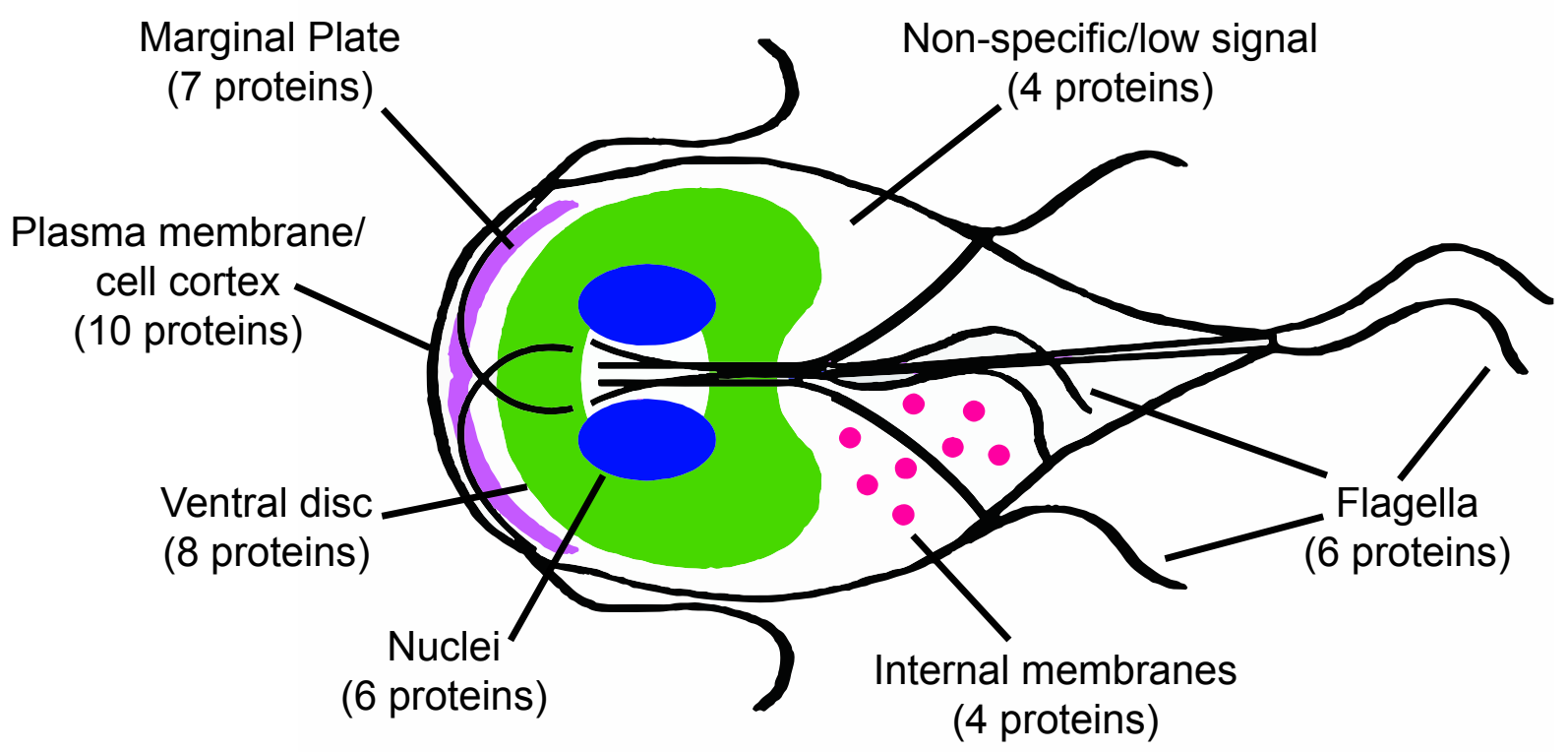

Figure 2: Localizations of GIActin Filament Interactors

594 Diagram of Giardia cell, with numbers of interactors localizing to each structure in

595 parentheses. Shown are the nuclei (blue), ventral disc (green), marginal plate (purple),

596 flagella and axonemes (black), internal membranes, (pink), plasma membrane (black),

597 and non-specific/low signal. Ventral flagella are shown in cyan for contrast. 

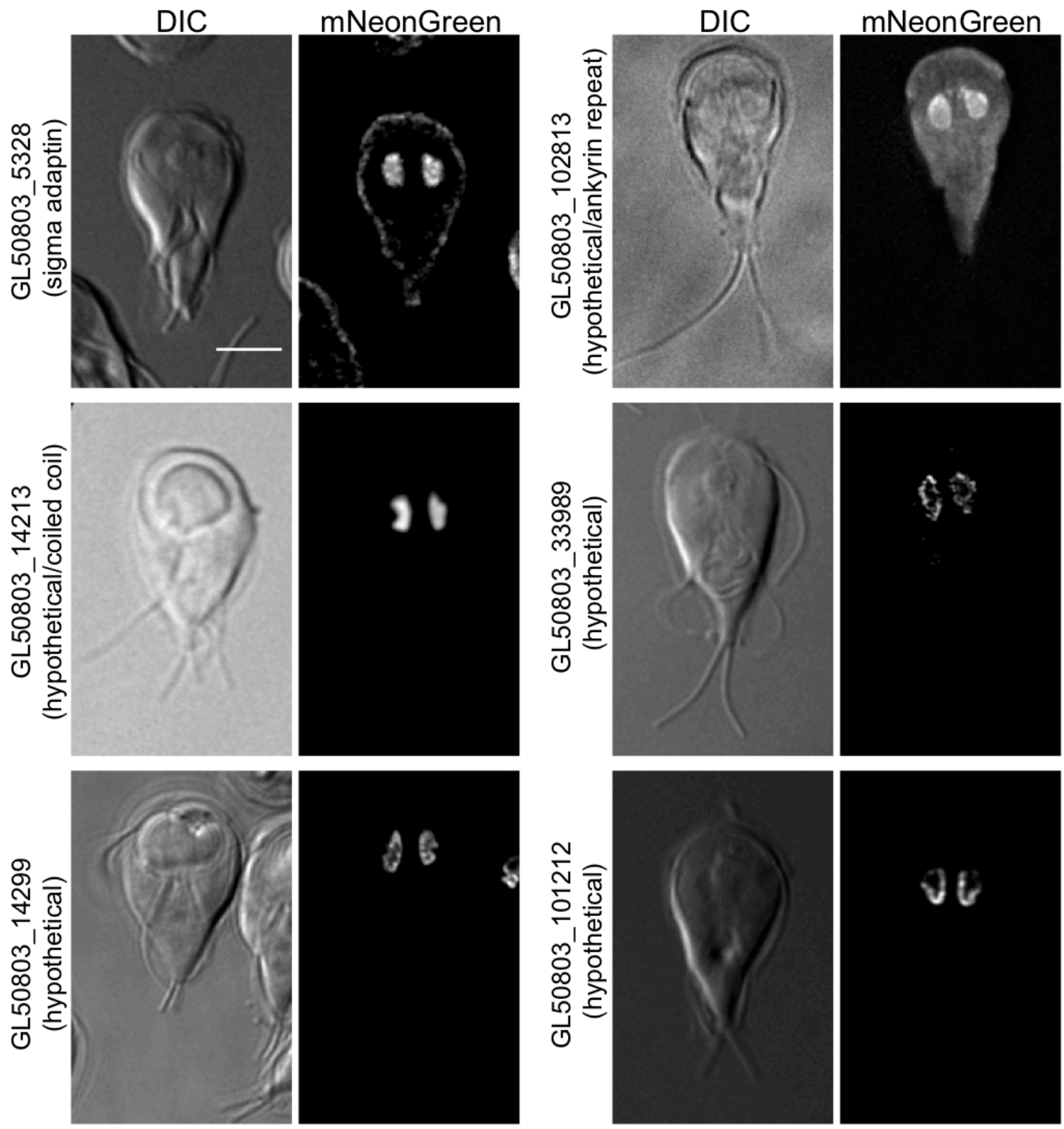

599 Figure 3: Putative GIActin interactors with nuclear localization Six proteins

600 identified localized to Giardia's nuclei based on the localization of mNeonGreen fusions.

601 GL50803_5238 localized to the plasma membrane as well as the nuclei.

602 GL50803_102813 also localized to the marginal plate and cytoplasm, with some puncta.

603 GL50803_GL14299 and GL50803_33989 appeared closer to the nuclear envelope, 
bioRxiv preprint doi: https://doi.org/10.1101/2021.05.19.444898; this version posted May 20, 2021. The copyright holder for this preprint (which

was not certified by peer review) is the author/funder, who has granted bioRxiv a license to display the preprint in perpetuity. It is made available under aCC-BY-NC-ND 4.0 International license.

604 while GL50803_101212 localized to the perinuclear region. GL50803_14213 was

605 evenly distributed within the nuclei. Scale bar, $5 \mu \mathrm{m}$.

606 

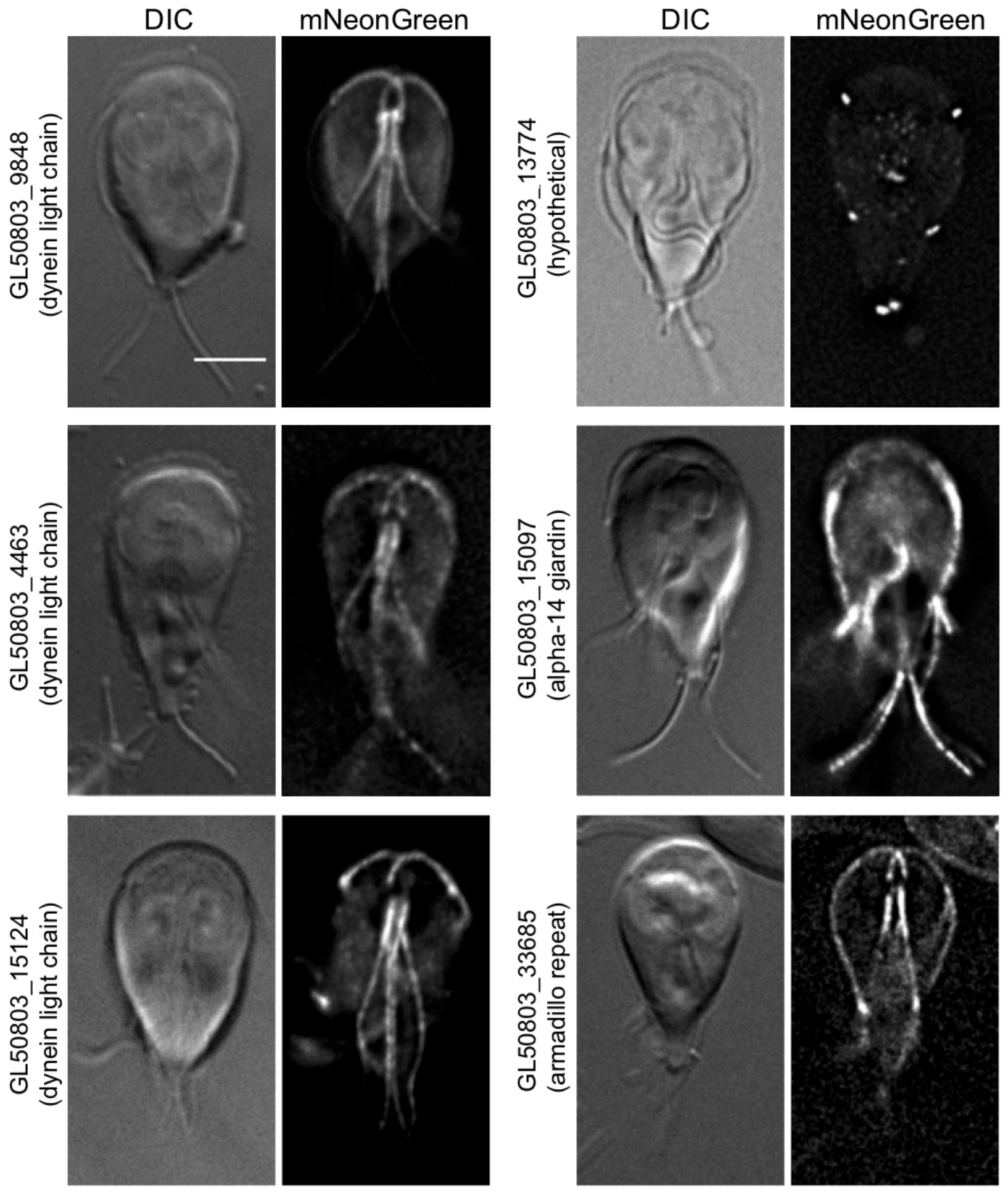

Figure 4: Putative GIActin interactors with flagella localization Six GIActin

609 interactors localized to flagella or flagella-related structures based on the localization of

610 mNeonGreen fusions. GL50803_15124 had a general flagellar localization. 
611 GL50803_4463 was enriched in the central axonemes, while GL50803_9848 was

612 enriched in the basal bodies. GL50803_15097 was enriched in posterolateral, ventral,

613 and caudal flagella. GL50803_33685 also appeared slightly in the plasma membrane.

614 GL50803_13774 was only present in the flagellar pores. Scale bar, $5 \mu \mathrm{m}$. 


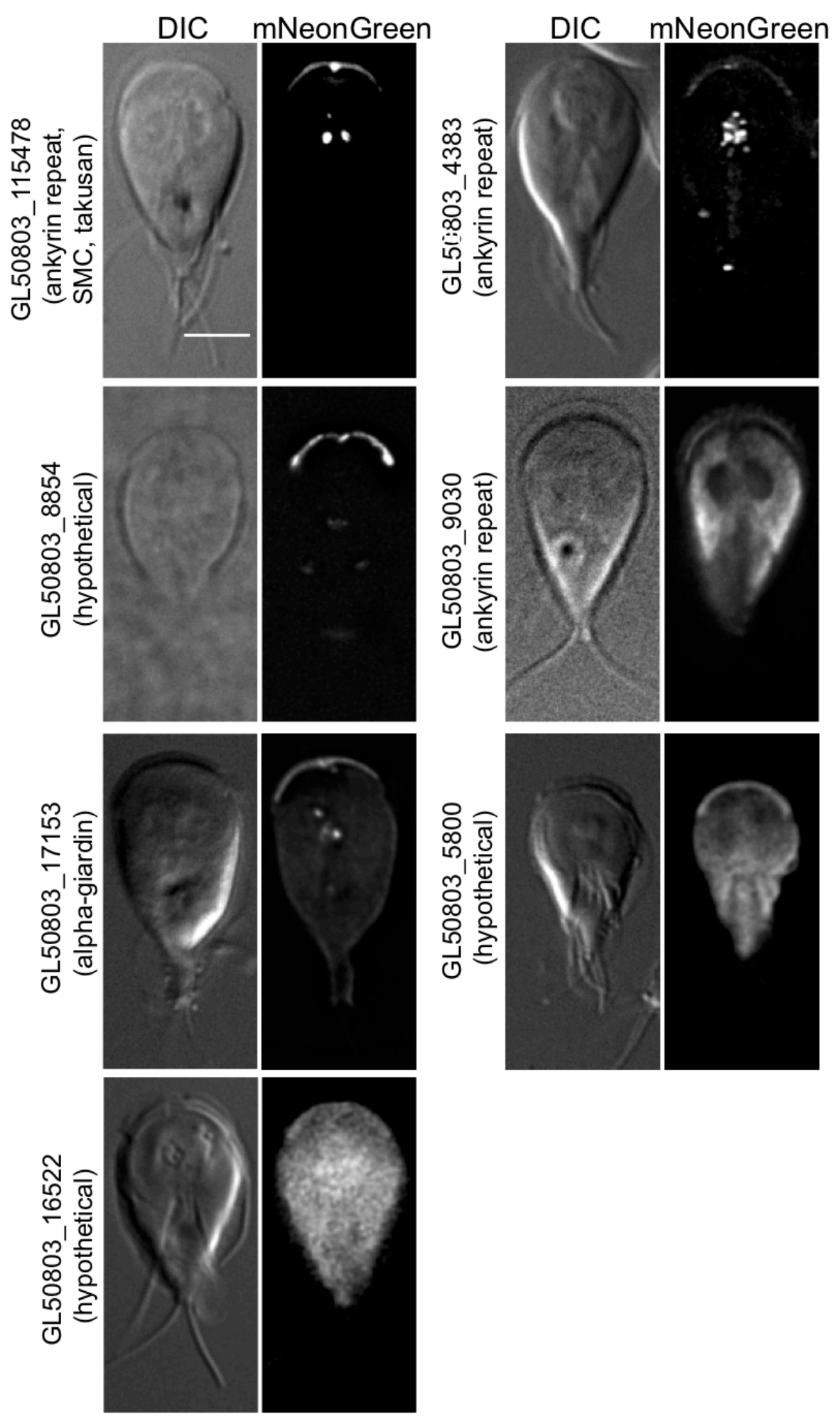

Figure 5: Putative GIActin interactors with marginal plate localization Seven

618 GIActin interactors localized to the marginal plate based on the localization of 
619 mNeonGreen fusions. GL50803_115478, GL50803_17153, and GL50803_4383 also

620 appeared in axoneme-associated structures. GL50803_8854 was enriched in the

621 flagellar pores. GL50803_5800 and GL16522 were only slightly enriched in the plate.

622 GL50803_9030 was additionally observed in linear arrays that may be filaments at the

623 anterior ventrolateral flange and also localized throughout the cytoplasm with

624 enrichment in the lateral shields, but was excluded from the nuclei. Scale bar, $5 \mu \mathrm{m}$.

625 


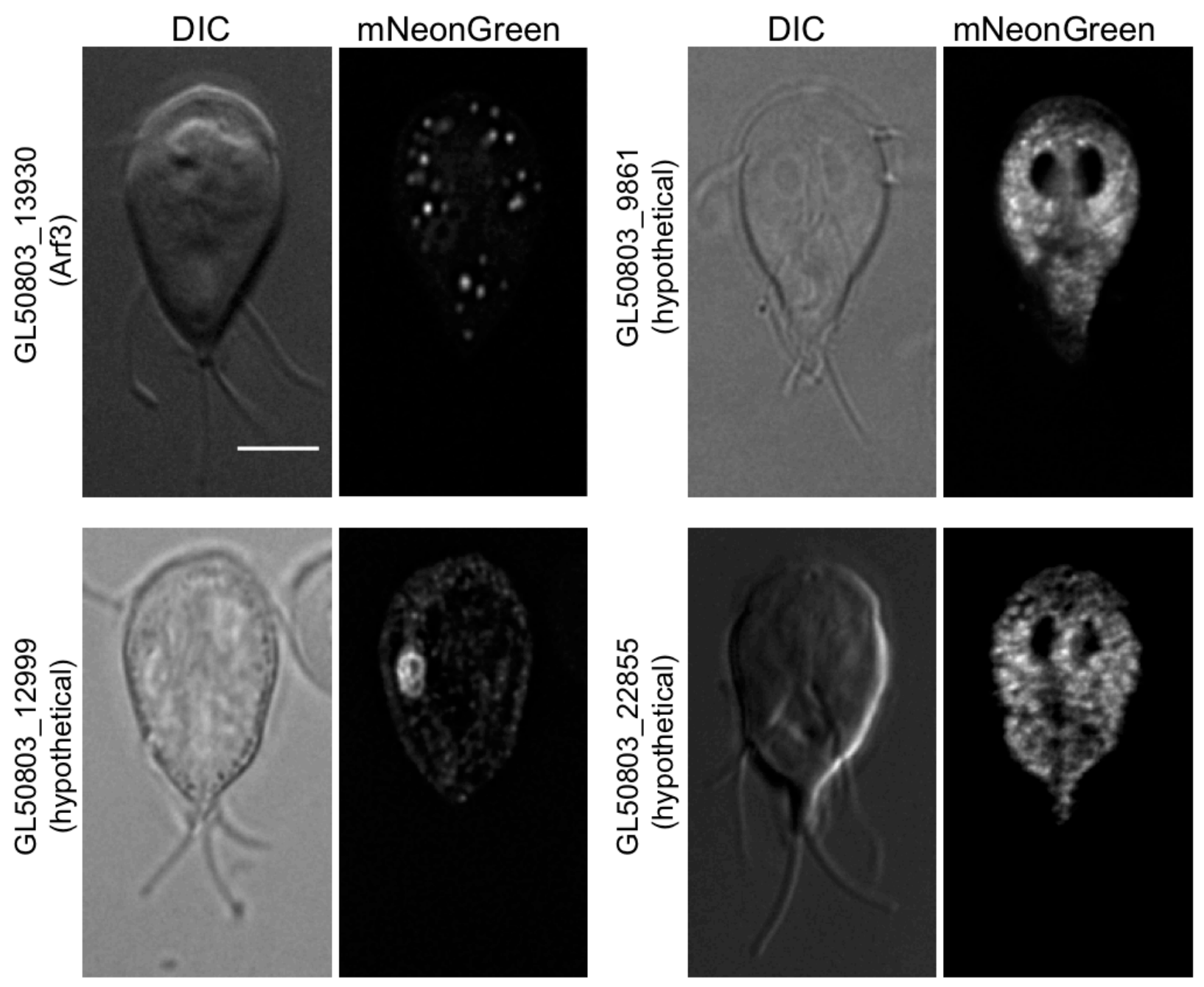

627 Figure 6: Putative GIActin interactors in the endomembrane system Four GIActin

628 interactors localized to internal structures likely to be the endomembrane system.

629 GL50803_22855 and GL50803_9861 were widely distributed throughout the cytoplasm,

630 GL50803_13930 was concentrated in a few stable puncta, and GL50803_12999

631 localized to cytoplasmic puncta and a large, oblong organelle. Except for Arf3, these

632 proteins are sometimes seen in linear arrays that could also indicate a connection to

633 actin filaments. Scale bar, $5 \mu \mathrm{m}$. 


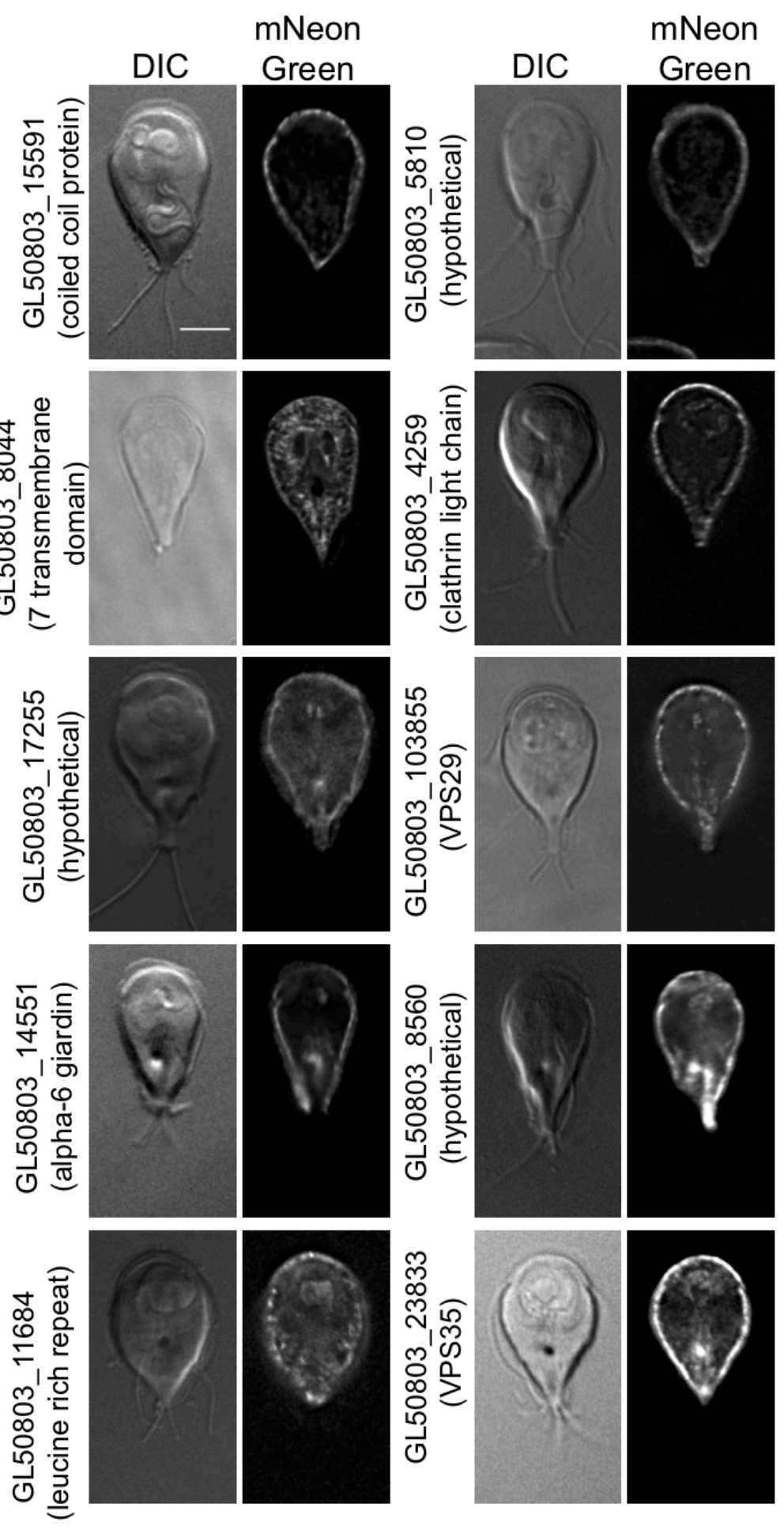

Figure 7: Putative GIActin interactors with cortical or plasma membrane

636 localization Ten GIActin interactors localized to the cell cortex based on the localization

637 of mNeonGreen fusions. Clathrin light chain GL50803_4259 is expected at the cell 
638 cortex. GL50803_5810 also had a slight localization to the nuclear envelope and

639 GL50803_8044 localized to the ER. Both GL50803_14551 and GL50803_17255

640 extended into the ventrolateral flange; the latter was also enriched in the basal bodies.

641 GL50803_103855, GL50803_23833, and GL50803_8560 had a slightly punctate

642 distribution within the plasma membrane. GL50803_15591 and GL50803_11684 were

643 even more punctate, with individual puncta clearly visible. Scale bar, $5 \mu \mathrm{m}$. 

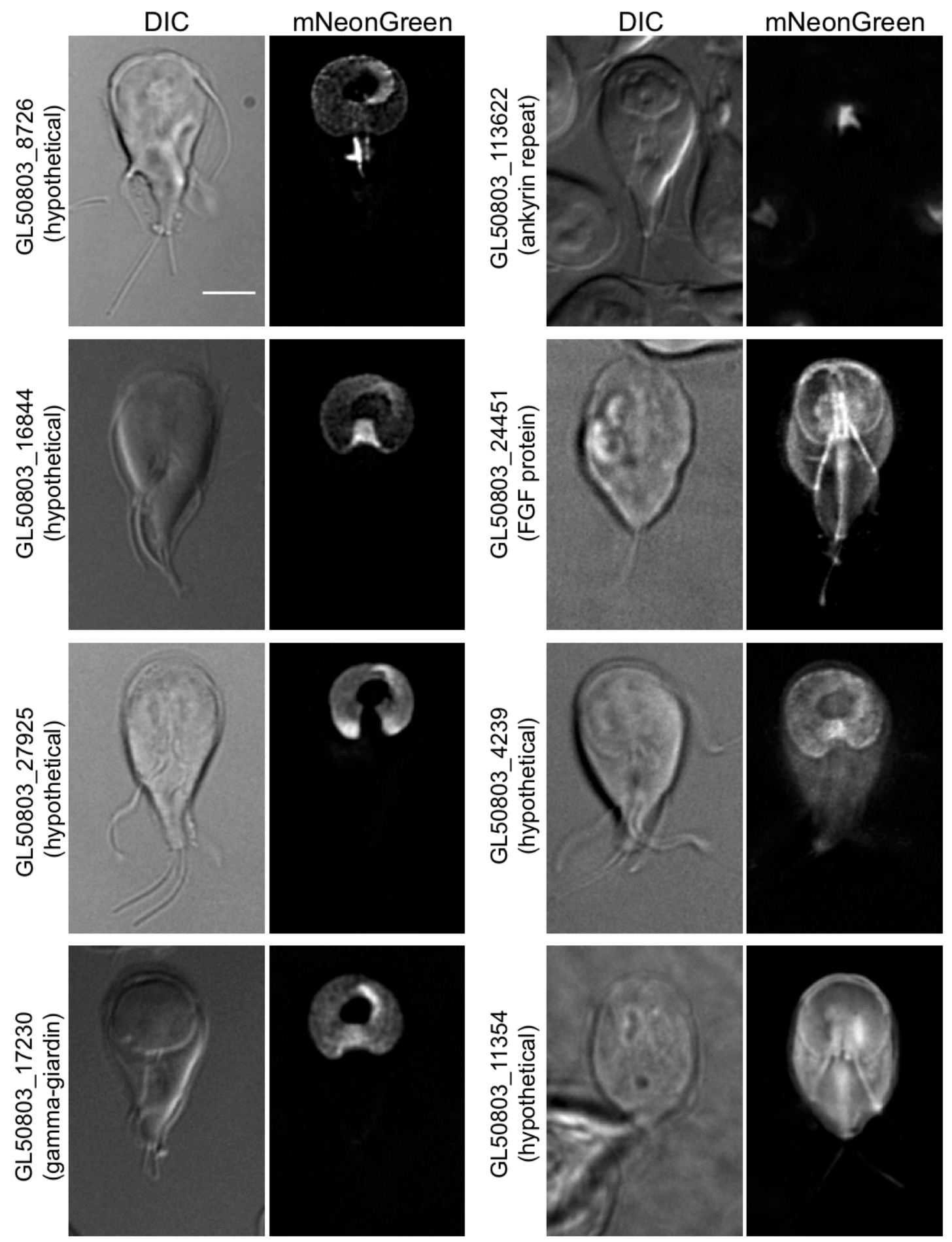

645 Figure 8: Putative GIActin Interactors with ventral disc localization Eight proteins

646 identified localized to the ventral disc based on mNeonGreen fusions. GL50803_8726

647 was more prominent on the disc margin and the overlap zone and appeared on the 
648 median body. GL50803_16844 was enriched in the ventral groove and the overlap

649 zone; GL50803_1720 was similarly enriched in the overlap zone. GL50803_4239 had a

650 slightly brighter signal in the ventral groove, the only place where GL50803_113622

651 localized. GL50803_11354 and GL50803_24451 faintly outlined both the ventral disc

652 and the flagella. GL50803_27925 is excluded from the ventral groove. Scale bar, $5 \mu \mathrm{m}$. 

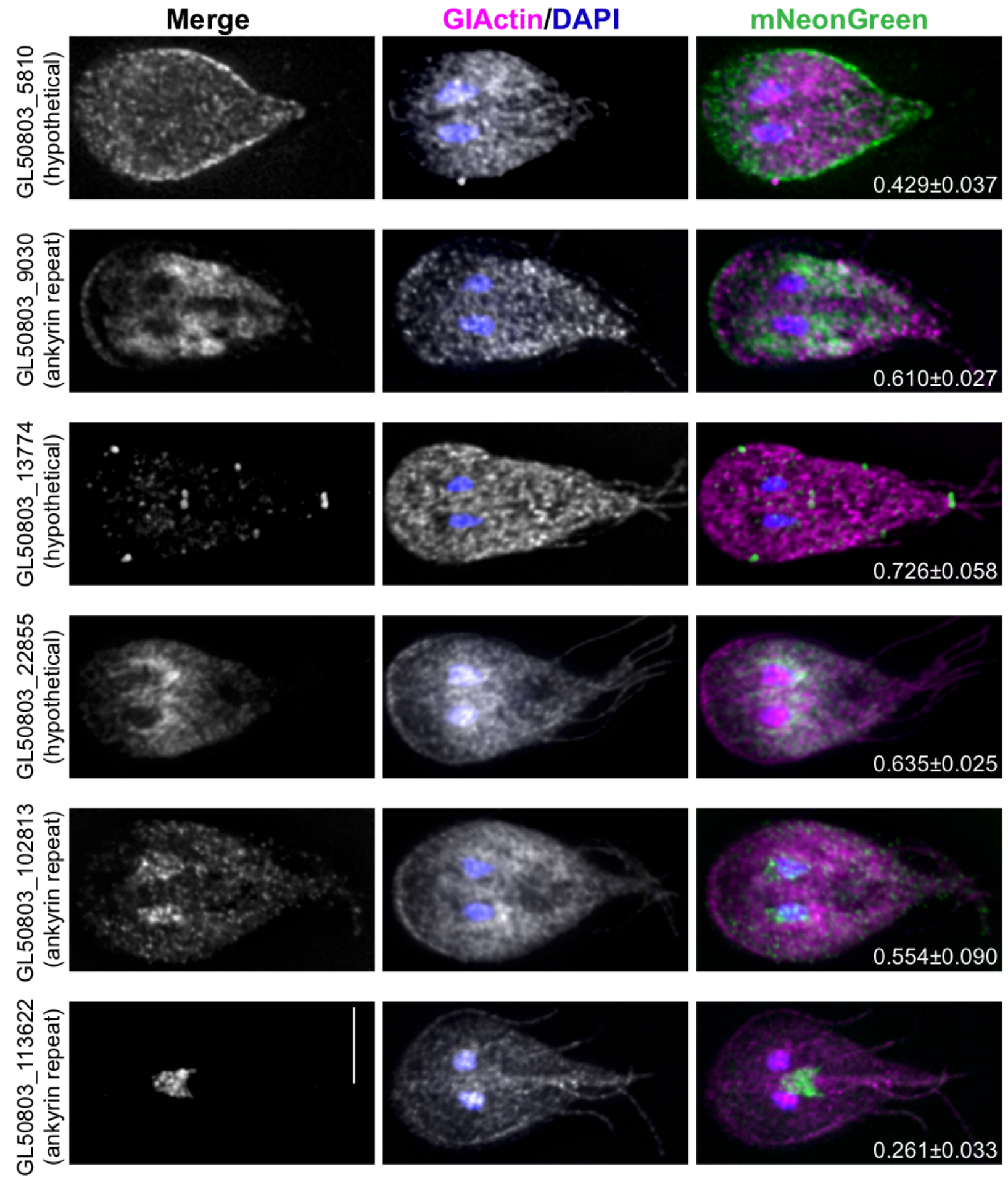

654 Figure 9: Immunostained GIActin is localized throughout the cell

655 One protein from each category of localization was co-localized with GlActin in fixed

656 Giardia trophozoites. Nuclei are stained with DAPI (blue), GIActin is magenta, and each 
bioRxiv preprint doi: https://doi.org/10.1101/2021.05.19.444898; this version posted May 20, 2021. The copyright holder for this preprint (which

was not certified by peer review) is the author/funder, who has granted bioRxiv a license to display the preprint in perpetuity. It is made available under aCC-BY-NC-ND 4.0 International license.

$657 \mathrm{mNeon}$ Green-tagged interactor is in green. Average projections are shown. Scale bar, 5

$658 \mu \mathrm{m}$. Pearson's correlation coefficients using Costes randomization were calculated for

659 three images of each protein, shown as mean $\pm S D$ on each merge. The Costes $P$-value

660 was 1 for all candidates.

661 


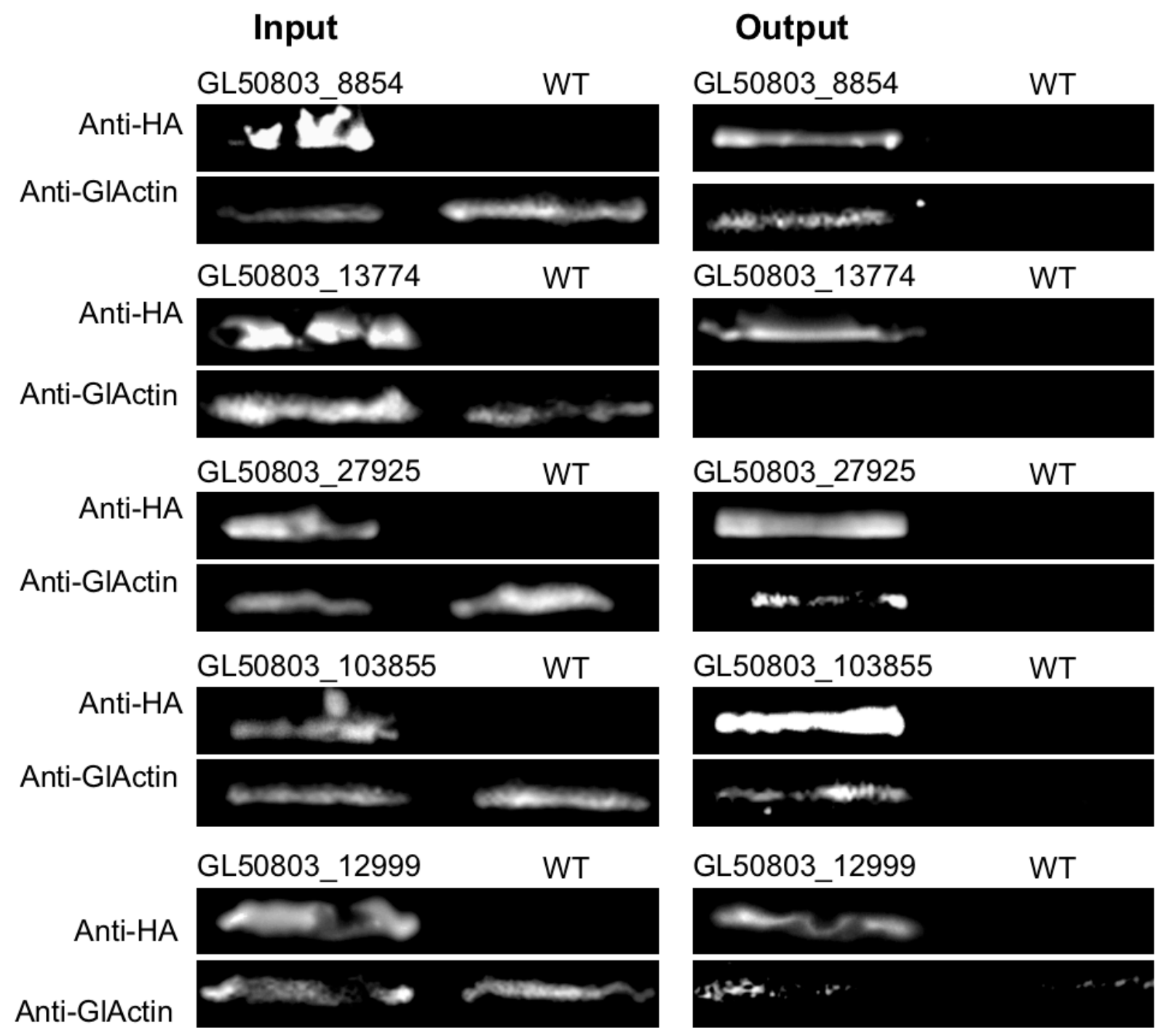

664 Figure 10: Reciprocal co-immunoprecipitation. One protein from each category of

665 localization was tagged with 3xHA and immunoprecipitated, followed by anti-G/Actin

666 Western blotting. Three of the six proteins tagged definitively complexed with GIActin,

667 including GL50803_8854 (marginal plate), GI50803_103855 (plasma membrane), and

668 GL50803_27925 (ventral disc). 
671 Table 1: Proteins identified as putative F-Actin interactors

ORF Number

Plasma

Membrane/Cortical

Localization

GL50803_8560

GL50803 23833

GL50803_4259

GL50803_8044

GL50803_15591

GL50803_14551 Alpha-6 giardin

GL50803_17255 Hypothetical

GL50803_5810

GL50803_11684

Internal Membrane

Localization

GL50803_9861

GL50803_13930

GL50803_22855

GL50803_12999

Marginal Plate

Localization

GL50803_17153

GL50803_115478

GL50803_8854

GL50803_4383

GL50803_5800
Identity

Hypothetical

VPS29

VPS35

Clathrin Light Chain

7-transmembrane domains

Coiled coil protein

Hypothetical

Leucine Rich Repeat Protein

Hypothetical

Arf3

Hypothetical

Hypothetical

Alpha-11 giardin

Ankyrin repeat, takusan, SMC

Hypothetical

Ankyrin repeat

Hypothetical
Localization

Plasma membrane

Plasma membrane

Plasma membrane

Plasma membrane

Plasma membrane and unidentified compartment

Plasma membrane

Ventrolateral flange and plasma membrane

Plasma membrane, flange, basal bodies

Plasma membrane

Plasma membrane

Diffuse internal membrane

Puncta

Vesicles

Puncta and unidentified

compartment
Marginal plate and axonemalassociated structures

Marginal plate and flagellar exit sites

Marginal plate and flagellar exit sites

Marginal plate and axonemalassociated structures

Marginal plate and puncta 


\begin{tabular}{|c|c|}
\hline GL50803_9030 & Ankyrin repeat \\
\hline $\begin{array}{l}\text { GL50803_16522 } \\
\text { Nuclear } \\
\text { Localization }\end{array}$ & Hypothetical \\
\hline GL50803_101212 & Hypothetical \\
\hline GL50803_33989 & Hypothetical \\
\hline GL50903_14299 & Hypothetical \\
\hline GL50803_5328 & $\begin{array}{l}\text { Sigma adaptin (AP2 } \\
\text { complex) }\end{array}$ \\
\hline GL50803_102813 & Ankyrin repeat \\
\hline GL50803_14213 & Hypothetical \\
\hline
\end{tabular}

$\begin{array}{ll}\text { GL50803_9848 } & \text { Dynein light chain } \\ \text { GL50803_33685 } & \text { Armadillo repeat } \\ \text { GL50803_15097 } & \text { Alpha-14 giardin } \\ \text { GL50803_13774 } & \text { Hypothetical } \\ \text { GL50803_4463 } & \text { Dynein light chain } \\ \text { GL50803_15124 } & \text { Dynein light chain }\end{array}$

Disc localization

$\begin{array}{ll}\text { GL50803_4239 } & \text { Hypothetical } \\ \text { GL50803_24451 } & \text { FGF } \\ \text { GL50803_8726 } & \text { Hypothetical } \\ \text { GL50803_27925 } & \text { Ankyrin repeat } \\ \text { GL50803_113622 } & \text { Ankyrin repeat } \\ \text { GL50803_16844 } & \text { Hypothetical } \\ \text { GL50803_17230 } & \text { Gamma-giardin } \\ \text { GL50803_11354 } & \text { Hypothetical }\end{array}$

Non-specific localization

$\begin{array}{ll}\text { GL50803_10038 } & \text { Alpha-18 giardin } \\ \text { GL50803_10429 } & \text { Wos2 protein } \\ \text { GL50803_7323 } & \text { Hypothetical }\end{array}$

Marginal plate and cytoplasmic puncta

Cytoplasmic, marginal disc, nuclei

\author{
Perinuclear region \\ Puncta and filaments within \\ nucleus \\ Diffuse nuclear localization with \\ puncta \\ Diffuse nuclear localization and \\ plasma membrane \\ Nuclear, marginal plate, \\ cytoplasmic \\ Diffuse nuclear localization with \\ puncta
}

Internal portions of flagella, basal bodies

Flagella

Flagella

Flagellar exit sites

Flagella

Flagella

Ventral disc, cytoplasmic

Flagella, basal bodies, lateral crest

Ventral disc, midbody

Ventral disc, except ventral groove

Ventral groove

Ventral disc: ventral groove and overlap zone

Ventral disc

Flagella, lateral crest
Diffuse non-specific
Diffuse non-specific
Diffuse non-specific 
GL50803_6242 tumor protein-like Diffuse non-specific

GL50803_21423 Beta-adaptin N/A

673 Supplemental Table 1: Previously validated GIActin interactors identified in this

674 screen

675

676 Supplemental Table 2: F- GIActin interactors which have been previously

677 localized

678

679 Supplemental Table 3: Complete list of proteins identified in this screen as

680 GIActin interactors

681

Supplemental Table 4: Primer sequences and workflow for tagging each protein

683

684 Acknowledgements: We thank Kelly Hennessey, Kelli Hvorecny, Han-wei Shih,

685 Elizabeth Thomas, and Germain Alas for manuscript editing.

686

687 This material is based upon work supported by the National Science Foundation

688 Graduate Research Fellowship under Grant No. DGE-1762114.

\section{References}

690

1. Pollard TD. 2016. Actin and Actin-Binding Proteins. Cold Spring Harbor Perspectives in Biology 8.

2. Oda T, Iwasa M, Aihara T, Maéda Y, Narita A. 2009. The nature of the globular- to 
3. Morrison HG, McArthur AG, Gillin FD, Aley SB, Adam RD, Olsen GJ, Best AA, Cande WZ, Chen F, Cipriano MJ, Davids BJ, Dawson SC, Elmendorf HG, Hehl AB, Holder ME, Huse SM, Kim UU, Lasek-Nesselquist E, Manning G, Nigam A, Nixon JEJ, Palm D, Passamaneck NE, Prabhu A, Reich Cl, Reiner DS, Samuelson J, Svard SG, Sogin ML. 2007. Genomic Minimalism in the Early Diverging Intestinal Parasite Giardia lamblia. Science 317.

4. Waingeh VF, Gustafson CD, Kozliak EI, Lowe SL, Knull HR, Thomasson KA. 2006. Glycolytic Enzyme Interactions with Yeast and Skeletal Muscle F-Actin. Biophysical Journal 90.

5. Drouin G, de Sá MM, Zuker M. 1995. The Giardia lamblia actin gene and the phylogeny of eukaryotes. Journal of Molecular Evolution 41.

6. Paredez AR, Assaf ZJ, Sept D, Timofejeva L, Dawson SC, Wang C-JR, Cande WZ. 2011. An actin cytoskeleton with evolutionarily conserved functions in the absence of canonical actin-binding proteins. Proceedings of the National Academy of Sciences 108.

7. Hardin WR, Li R, Xu J, Shelton AM, Alas GCM, Minin VN, Paredez AR. 2017. Myosinindependent cytokinesis in Giardia utilizes flagella to coordinate force generation and direct membrane trafficking. Proceedings of the National Academy of Sciences 114.

8. Dawson SC, Paredez AR. 2013. Alternative cytoskeletal landscapes: cytoskeletal novelty and evolution in basal excavate protists. Current Opinion in Cell Biology 25.

9. Savioli L, Smith H, Thompson A. 2006. Giardia and Cryptosporidium join the 'Neglected Diseases Initiative.' Trends in Parasitology 22.

10. Paredez AR, Nayeri A, Xu JW, Krtková J, Cande WZ. 2014. Identification of Obscure yet Conserved Actin-Associated Proteins in Giardia lamblia. Eukaryotic Cell 13.

11. Prucca CG, Lujan HD. 2009. Antigenic variation in Giardia lamblia. Cellular Microbiology 11.

12. Nash TE, Luján HT, Mowatt MR, Conrad JT. 2001. Variant-Specific Surface Protein Switching inGiardia lamblia. Infection and Immunity 69.

13. Krtková J, Xu J, Lalle M, Steele-Ogus M, Alas GCM, Sept D, Paredez AR. 2017. 14-3-3 Regulates Actin Filament Formation in the Deep-Branching Eukaryote Giardia lamblia. mSphere 2.

14. Khadijeh Falahzadeh AB-E and MS. 2015. The Potential Roles Of Actin In The Nucleus. Cell J 17:7-14.

15. Einarsson E, Troell K, Hoeppner MP, Grabherr M, Ribacke U, Svärd SG. 2016. Coordinated Changes in Gene Expression Throughout Encystation of Giardia intestinalis. PLOS Neglected Tropical Diseases 10.

16. Aurrecoechea C, Barreto A, Basenko EY, Brestelli J, Brunk BP, Cade S, Crouch K, Doherty R, Falke D, Fischer S, Gajria B, Harb OS, Heiges M, Hertz-Fowler C, Hu S, lodice J, Kissinger JC, Lawrence C, Li W, Pinney DF, Pulman JA, Roos DS, Shanmugasundram A, Silva-Franco F, Steinbiss S, Stoeckert CJ, Spruill D, Wang H, Warrenfeltz S, Zheng J. 2017. EuPathDB: the eukaryotic pathogen genomics database resource. Nucleic Acids Research 45. 
17. Aurrecoechea C, Brestelli J, Brunk BP, Carlton JM, Dommer J, Fischer S, Gajria B, Gao X, Gingle A, Grant G, Harb OS, Heiges M, Innamorato F, lodice J, Kissinger JC, Kraemer E, Li W, Miller JA, Morrison HG, Nayak V, Pennington C, Pinney DF, Roos DS, Ross C, Stoeckert CJ, Sullivan S, Treatman C, Wang H. 2009. GiardiaDB and TrichDB: integrated genomic resources for the eukaryotic protist pathogens Giardia lamblia and Trichomonas vaginalis. Nucleic Acids Research 37.

18. Nohýnková E, Tůmová P, Kulda J. 2006. Cell Division of Giardia intestinalis: Flagellar Developmental Cycle Involves Transformation and Exchange of Flagella between Mastigonts of a Diplomonad Cell. Eukaryotic Cell 5.

19. Lenaghan SC, Davis CA, Henson WR, Zhang Z, Zhang M. 2011. High-speed microscopic imaging of flagella motility and swimming in Giardia lamblia trophozoites. Proceedings of the National Academy of Sciences 108.

20. Yanagisawa H, Kamiya R. 2001. Association between Actin and Light Chains in Chlamydomonas Flagellar Inner-Arm Dyneins. Biochemical and Biophysical Research Communications 288.

21. Avasthi P, Onishi M, Karpiak J, Yamamoto R, Mackinder L, Jonikas MC, Sale WS, Shoichet B, Pringle JR, Marshall WF. 2014. Actin Is Required for IFT Regulation in Chlamydomonas reinhardtii. Current Biology 24.

22. Gervasi MG, Xu X, Carbajal-Gonzalez B, Buffone MG, Visconti PE, Krapf D. 2018. The actin cytoskeleton of the mouse sperm flagellum is organized in a helical structure. Journal of Cell Science 131.

23. Mclnally SG, Dawson SC. 2016. Eight unique basal bodies in the multi-flagellated diplomonad Giardia lamblia. Cilia 5.

24. Maia-Brigagão C, Gadelha APR, de Souza W. 2013. New Associated Structures of the Anterior Flagella of Giardia duodenalis. Microscopy and Microanalysis 19.

25. Gadelha APR, Benchimol M, de Souza W. 2015. Helium ion microscopy and ultrahigh-resolution scanning electron microscopy analysis of membrane-extracted cells reveals novel characteristics of the cytoskeleton of Giardia intestinalis. Journal of Structural Biology 190.

26. Hagen KD, Mclnally SG, Hilton ND, Dawson SC. 2020. Microtubule organelles in Giardia.

27. Dolezal P, Smid O, Rada P, Zubacova Z, Bursac D, Sutak R, Nebesarova J, Lithgow T, Tachezy J. 2005. Giardia mitosomes and trichomonad hydrogenosomes share a common mode of protein targeting. Proceedings of the National Academy of Sciences 102.

28. Voleman L, Najdrová V, Ástvaldsson Á, Tůmová P, Einarsson E, Švindrych Z, Hagen GM, Tachezy J, Svärd SG, Doležal P. 2017. Giardia intestinalis mitosomes undergo synchronized fission but not fusion and are constitutively associated with the endoplasmic reticulum. BMC Biology 15.

29. Nosala C, Hagen KD, Dawson SC. 2018. 'Disc-o-Fever': Getting Down with Giardia's Groovy Microtubule Organelle. Trends in Cell Biology 28.

30. Krtková J, Thomas EB, Alas GCM, Schraner EM, Behjatnia HR, Hehl AB, Paredez AR. 2016. Rac Regulates Giardia lamblia Encystation by Coordinating Cyst Wall Protein Trafficking and Secretion. mBio 7. 
31. Faso C, Konrad C, Schraner EM, Hehl AB. 2013. Export of cyst wall material and Golgi organelle neogenesis in Giardia lamblia depend on endoplasmic reticulum exit sites. Cellular Microbiology 15.

32. Hardin WR, M Alas GC, Taparia N, Thomas EB, Hvorecny KL, Halpern AR, Tůmová P, Vaughan JC, Sniadecki NJ, Paredez AR. The Giardia lamellipodium-like ventrolateral flange supports attachment and rapid cytokinesis https://doi.org/10.1101/2021.01.31.429041.

33. ERLANDSEN SL, RUSSO AP, TURNER JN. 2004. Evidence for Adhesive Activity of the Ventrolateral Flange in Giardia lamblia. The Journal of Eukaryotic Microbiology 51.

34. Schwartz CL, Heumann JM, Dawson SC, Hoenger A. 2012. A Detailed, Hierarchical Study of Giardia lamblia's Ventral Disc Reveals Novel Microtubule-Associated Protein Complexes. PLoS ONE 7.

35. Elmendorf HG, Dawson SC, McCaffery JM. 2003. The cytoskeleton of Giardia lamblia. International Journal for Parasitology 33.

36. Hardin WR, Li R, Xu J, Shelton AM, Alas GCM, Minin VN, Paredez AR. 2017. Myosinindependent cytokinesis in Giardia utilizes flagella to coordinate force generation and direct membrane trafficking. Proceedings of the National Academy of Sciences 114.

37. Tee J-M, Peppelenbosch MP. 2010. Anchoring skeletal muscle development and disease: the role of ankyrin repeat domain containing proteins in muscle physiology. Critical Reviews in Biochemistry and Molecular Biology 45.

38. Liu Y, Li X, He Y, Wang H, Gao M, Han L, Qiu D, Ling L, Liu H, Gu L. 2020. ASB7 Is a Novel Regulator of Cytoskeletal Organization During Oocyte Maturation. Frontiers in Cell and Developmental Biology 8.

39. Morgan RO, Fernández M-P. 1995. Molecular phylogeny of annexins and identification of a primitive homologue in Giardia lamblia. Molecular Biology and Evolution https://doi.org/10.1093/oxfordjournals.molbev.a040290.

40. Hayes MJ, Rescher U, Gerke V, Moss SE. 2004. Annexin-Actin Interactions. Traffic 5.

41. Boye TL, Nylandsted J. 2016. Annexins in plasma membrane repair. Biological Chemistry 397.

42. Serebryannyy L, de Lanerolle P. 2020. Nuclear actin: The new normal. Mutation Research/Fundamental and Molecular Mechanisms of Mutagenesis 821.

43. Zhao K, Wang W, Rando OJ, Xue Y, Swiderek K, Kuo A, Crabtree GR. 1998. Rapid and Phosphoinositol-Dependent Binding of the SWI/SNF-like BAF Complex to Chromatin after T Lymphocyte Receptor Signaling. Cell 95.

44. Pfisterer K, Jayo A, Parsons M. 2017. Control of nuclear organization by F-actin binding proteins. Nucleus 8.

45. Davidson PM, Cadot B. 2020. Actin on and around the Nucleus. Trends in Cell Biology https://doi.org/10.1016/j.tcb.2020.11.009.

46. Mettlen M, Chen P-H, Srinivasan S, Danuser G, Schmid SL. 2018. Regulation of Clathrin-Mediated Endocytosis. Annual Review of Biochemistry 87.

47. Zumthor JP, Cernikova L, Rout S, Kaech A, Faso C, Hehl AB. 2016. Static Clathrin Assemblies at the Peripheral Vacuole-Plasma Membrane Interface of the Parasitic Protozoan Giardia lamblia. PLOS Pathogens 12. 
48. Hehl AB, Faso C. 2017. Response to Zamponi et al . Trends in Parasitology 33.

49. Zamponi N, Feliziani C, Touz MC. 2016. Endocytosis in Giardia : Evidence of Absence. Trends in Parasitology 32.

50. Rojas-Gutiérrez O, Pérez-Rangel A, Castillo-Romero A, Tapia-Ramírez J, Ríos-Castro E, Camacho-Nuez M, Giono-Cerezo S, Nogueda-Torres B, León-Avila G, Hernández JM. 2021. Giardia intestinalis coiled-coil cytolinker protein 259 interacts with actin and tubulin. Parasitology Research https://doi.org/10.1007/s00436-021-07062-6.

51. Zumthor JP, Cernikova L, Rout S, Kaech A, Faso C, Hehl AB. 2016. Static Clathrin Assemblies at the Peripheral Vacuole-Plasma Membrane Interface of the Parasitic Protozoan Giardia lamblia. PLOS Pathogens 12.

52. Rivero MR, Vranych CV, Bisbal M, Maletto BA, Ropolo AS, Touz MC. 2010. Adaptor protein 2 regulates receptor-mediated endocytosis and cyst formation in Giardia lamblia. Biochemical Journal 428.

53. Boehm M, Bonifacino JS. 2002. Genetic analyses of adaptin function from yeast to mammals. Gene 286.

54. Fan L, Hao H, Xue Y, Zhang L, Song K, Ding Z, Botella MA, Wang H, Lin J. 2013. Dynamic analysis of Arabidopsis AP2 subunit reveals a key role in clathrin-mediated endocytosis and plant development. Development 140.

55. Boehm M, Bonifacino JS. 2001. Adaptins. Molecular Biology of the Cell 12.

56. Brodsky FM, Sosa RT, Ybe JA, O'Halloran TJ. 2014. Unconventional Functions for Clathrin, ESCRTs, and Other Endocytic Regulators in the Cytoskeleton, Cell Cycle, Nucleus, and Beyond: Links to Human Disease. Cold Spring Harbor Perspectives in Biology 6.

57. Collins BM. 2008. The Structure and Function of the Retromer Protein Complex. Traffic 9.

58. Miras SL, Merino MC, Gottig N, Rópolo AS, Touz MC. 2013. The giardial VPS35 retromer subunit is necessary for multimeric complex assembly and interaction with the vacuolar protein sorting receptor. Biochimica et Biophysica Acta (BBA) Molecular Cell Research 1833.

59. Seaman MNJ. 2012. The retromer complex - endosomal protein recycling and beyond. Journal of Cell Science 125.

60. Benchimol M. 2020. Giardia intestinalis can interact, change its shape and internalize large particles and microorganisms. Parasitology https://doi.org/10.1017/S0031182020002292.

61. May RC, Machesky LM. 2001. Phagocytosis and the actin cytoskeleton. Journal of Cell Science 114:1061-1077.

62. Gui M, Ma M, Sze-Tu E, Wang X, Koh F, Zhong ED, Berger B, Davis JH, Dutcher SK, Zhang R, Brown A. 2021. Structures of radial spokes and associated complexes important for ciliary motility. Nature Structural \& Molecular Biology 28.

63. Wieczorek M, Urnavicius L, Ti S-C, Molloy KR, Chait BT, Kapoor TM. 2020. Asymmetric Molecular Architecture of the Human $\gamma$-Tubulin Ring Complex. Cell 180.

64. Kato-Minoura T, Hirono M, Kamiya R. 1997. Chlamydomonas Inner-Arm Dynein Mutant, ida5, Has a Mutation in an Actin-encoding Gene. Journal of Cell Biology 137. 
65. Avasthi P, Onishi M, Karpiak J, Yamamoto R, Mackinder L, Jonikas MC, Sale WS, Shoichet B, Pringle JR, Marshall WF. 2014. Actin Is Required for IFT Regulation in Chlamydomonas reinhardtii. Current Biology 24.

66. Jack B, Mueller DM, Fee AC, Tetlow AL, Avasthi P. 2019. Partially Redundant Actin Genes in Chlamydomonas Control Transition Zone Organization and FlagellumDirected Traffic. Cell Reports 27.

67. Gadelha APR, Benchimol M, Souza W de. 2017. The Cytoskeleton of Giardia intestinalisCurrent Topics in Giardiasis. InTech.

68. Feely DE, Schollmeyer J v., Erlandsen SL. 1982. Giardia spp.: Distribution of contractile proteins in the attachment organelle. Experimental Parasitology 53.

69. Nosala C, Dawson SC. 2017. The ventral disc is a flexible microtubule organelle that depends on domed ultrastructure for functional attachment of Giardia lamblia. bioRxiv. bioRxiv.

70. Kim J, Park S-J. 2019. Role of gamma-giardin in ventral disc formation of Giardia lamblia. Parasites \& Vectors 12.

71. Hagen KD, Hirakawa MP, House SA, Schwartz CL, Pham JK, Cipriano MJ, de La Torre MJ, Sek AC, Du G, Forsythe BM, Dawson SC. 2011. Novel Structural Components of the Ventral Disc and Lateral Crest in Giardia intestinalis. PLoS Neglected Tropical Diseases 5.

72. Sagolla MS, Dawson SC, Mancuso JJ, Cande WZ. 2006. Three-dimensional analysis of mitosis and cytokinesis in the binucleate parasite Giardia intestinalis. Journal of Cell Science 119.

73. Eng JK, Jahan TA, Hoopmann MR. 2013. Comet: An open-source MS/MS sequence database search tool. PROTEOMICS 13.

74. Keller A, Nesvizhskii Al, Kolker E, Aebersold R. 2002. Empirical Statistical Model To Estimate the Accuracy of Peptide Identifications Made by MS/MS and Database Search. Analytical Chemistry 74.

75. Nesvizhskii Al, Keller A, Kolker E, Aebersold R. 2003. A Statistical Model for Identifying Proteins by Tandem Mass Spectrometry. Analytical Chemistry 75.

76. Fermin D, Basrur V, Yocum AK, Nesvizhskii Al. 2011. Abacus: A computational tool for extracting and pre-processing spectral count data for label-free quantitative proteomic analysis. PROTEOMICS 11.

77. Deutsch EW, Bandeira N, Sharma V, Perez-Riverol Y, Carver JJ, Kundu DJ, GarcíaSeisdedos D, Jarnuczak AF, Hewapathirana S, Pullman BS, Wertz J, Sun Z, Kawano S, Okuda S, Watanabe Y, Hermjakob H, MacLean B, MacCoss MJ, Zhu Y, Ishihama Y, Vizcaíno JA. 2019. The ProteomeXchange consortium in 2020: enabling 'big data' approaches in proteomics. Nucleic Acids Research https://doi.org/10.1093/nar/gkz984.

78. Perez-Riverol Y, Csordas A, Bai J, Bernal-Llinares M, Hewapathirana S, Kundu DJ, Inuganti A, Griss J, Mayer G, Eisenacher M, Pérez E, Uszkoreit J, Pfeuffer J, Sachsenberg T, Yılmaz Ş, Tiwary S, Cox J, Audain E, Walzer M, Jarnuczak AF, Ternent T, Brazma A, Vizcaíno JA. 2019. The PRIDE database and related tools and resources in 2019: improving support for quantification data. Nucleic Acids Research 47. 
79. Hennessey KM, Alas GCM, Rogiers I, Li R, Merritt EA, Paredez AR. 2020. Nek8445, a protein kinase required for microtubule regulation and cytokinesis in Giardia lamblia. Molecular Biology of the Cell 31.

80. Krtková J, Thomas EB, Alas GCM, Schraner EM, Behjatnia HR, Hehl AB, Paredez AR. 2016. Rac Regulates Giardia lamblia Encystation by Coordinating Cyst Wall Protein Trafficking and Secretion. mBio 7.

81. BOLTE S, CORDELIÈRES FP. 2006. A guided tour into subcellular colocalization analysis in light microscopy. Journal of Microscopy 224. 